\title{
EL ARBITRAJE DE INVERSIONES EN LOS TRATADOS DE LIBRE COMERCIO DE NUEVA GENERACIÓN: UN ANÁLISIS NACIONAL DESDE LA PERSPECTIVA DEL DERECHO A LA TUTELA JUDICIAL EFECTIVA
}

\author{
THE INVESTMENT ARBITRATION IN THE NEW \\ GENERATION FREE TRADE AGREEMENTS: A NATIONAL \\ ANALYSIS FROM THE PERSPECTIVE OF THE RIGHT \\ TO AN EFFECTIVE JUDICIAL REMEDY
}

\author{
Guillermo SchumanN BarRagán \\ Contratado Predoctoral FPU \\ Departamento de Derecho Procesal y Derecho Penal \\ Universidad Complutense de Madrid \\ ORCID ID: 0000-0003-1934-7808
}

Recibido: 11.06.2020 / Aceptado: 25.06.2020

DOI: https://doi.org/10.20318/cdt.2020.5678

\begin{abstract}
Resumen: En este trabajo se analiza el sistema de solución de diferencias en materia de inversiones extranjeras en los tratados de libre comercio de nueva generación desde la perspectiva del derecho a la tutela judicial efectiva. En concreto, se examina la compatibilidad del arbitraje de inversiones del CETA con los arts. 47 CDFUE, 6 CEDH y 24 CE.

Palabras clave: arbitraje de inversiones, CETA, derecho a la tutela judicial efectiva, art. 47 CDFUE, art. $24 \mathrm{CE}$, art. 6 CEDH.

Abstract: This paper analyzes the mechanism for investor-State dispute settlement in the new generation free trade agreements from the perspective of the right to an effective judicial remedy. In particular, it examines the compatibility of the CETA investment arbitration with Articles. 47 CFREU, 6 ECHR and 24 of the Spanish Constitution.
\end{abstract}

Keywords: investment arbitration, CETA, right to an effective judicial remedy, Art. 47 CFREU, Art. 24 CE, Art. 6 ECHR.

Sumario: I. Introducción. II. El sistema de solución de diferencias en materia de inversiones en los tratados de libre comercio de nueva generación. 2.1. Una competencia compartida entre la UE y sus EE. MM.; 2.2. Un cambio de modelo. III. La compatibilidad del sistema de solución de diferencias en materia de inversiones con el art. 47 CDFUE. 3.1. La externalización y dimensión objetiva del art. 47 CDFUE; 3.2. La compatibilidad del CETA con el art. 47 CDFUE. IV. La solución de diferencias en materia de inversiones: ¿tribunal o arbitraje internacional? 4.1. El «tribunal» permanente de inversiones: ¿una jurisdicción internacional?; 4.2. El «tribunal» permanente de inversiones: un arbitraje internacional obligatorio. V. Un análisis desde la perspectiva del derecho a la tutela judicial efectiva. 5.1. La compatibilidad del arbitraje de inversiones del CETA con el art. 24 CE; 5.2. La compatibilidad del arbitraje de inversiones del CETA con el art. 6 CEDH. VI. Excurso: a la espera del Tribunal Constitucional alemán. VII. Conclusión. 


\section{Introducción}

1. Este artículo tiene como finalidad analizar desde una perspectiva nacional la compatibilidad del sistema de solución de diferencias en materia de inversiones en los tratados de libre comercio de nueva generación celebrados por la UE y España con el derecho a la tutela judicial efectiva. ${ }^{1}$

2. Este análisis en relación con el art. 47 CDFUE ya lo ha hecho el Tribunal de Justicia de la UE (TJUE) en su Dictamen 1/17 de 30 de abril de 2019 (Acuerdo Económico y Comercial Global entre Canadá y la UE y sus EE. MM. [CETA]). En la medida en que el CETA se ha considerado un golden standard o blue print para la negociación de futuros acuerdos, buena parte de las conclusiones que respecto de él se alcancen podrán ser extrapoladas al resto de tratados que incorporen un modelo similar.

3. El Dictamen $1 / 17$, por su parte, se enmarca en una serie de resoluciones del Tribunal que afectan directamente a la arquitectura constitucional de la UE y que sientan las bases para la apertura del ordenamiento comunitario al internacional y la interrelación entre ambos. En especial, resulta clave el modo en que se aborda la autonomía del Derecho de la UE y su materialización práctica en la protección de la cuestión prejudicial y la competencia del TJUE como su último interprete. Es de interés comprobar que con la posibilidad de pronunciarse sobre la compatibilidad de los tratados internacionales proyectados con el ordenamiento comunitario (art. 218.11 TFUE) - $-\mathrm{y}$, como parte principal de él, con la CDFUE - el TJUE actúa de forma similar a como lo haría un tribunal constitucional nacional. ${ }^{2}$

4. Para alcanzar el objetivo propuesto se llevará a cabo un análisis del cambio de modelo que suponen los tratados de libre comercio de nueva generación para el arbitraje de inversiones extranjeras (II); una exposición de la doctrina del TJUE en su Dictamen 1/17 en relación con la compatibilidad del CETA con el art. 47 CDFUE (III); un apunte sobre la naturaleza jurisdiccional o arbitral del sistema diseñado (IV); y un examen de su compatibilidad con el derecho a la tutela judicial efectiva (V).

\section{El sistema de solución de diferencias en materia de inversiones en los tratados de libre comercio de nueva generación}

\subsection{Una competencia compartida entre la UE y sus Estados Miembros}

5. El sistema de protección de inversiones extranjeras se ha incluido tradicionalmente en los acuerdos bilaterales de promoción y protección recíproca de inversiones (APPRIS). Los denominados tratados de libre comercio de nueva generación son aquellos que, además de la habitual reducción de derechos arancelarios, incorporan materias relativas a la protección de derechos de propiedad industrial, contratación pública, competencia, medio ambiente, desarrollo sostenible y, en lo que ahora nos interesa, protección de inversiones. ${ }^{3}$ De esta manera, aunque en abstracto puedan seguir celebrándose de forma separada con terceros países, ${ }^{4}$ la intención será que la función que llevaban a cabo los APPRIS se incorpore en los tratados de libre comercio.

\footnotetext{
${ }^{1}$ Este trabajo se enmarca dentro del Proyecto de Investigación "Hacia un proceso civil convergente con Europa. Hitos presentes y retos futuros" (PGC2018-094693-B-I00), financiado por el Ministerio de Ciencia, Innovación y Universidades.

${ }^{2}$ Se trata de lo que la doctrina alemana ha denominado die verfassungsrechtliche Argumentation des EuGH: vid. S. STÖBener de Mora, S. WernicKe, "Riskante Vorgaben für Investitionsschutz und Freihandel - Das CETA-Gutachten des EuGH", EuZW, 2019, núm. 23, p. 973.

${ }^{3}$ El impulso y promoción de los tratados de libre comercio de nueva generación en el seno de la UE se entiende como una reacción y necesidad frente a la crisis del multilateralismo en la OMC en los últimos años. En este sentido vid. J. C. FERNÁNDEZ RozAs, "Permanencia y expansión del bilateralismo: Los acuerdos comerciales de nueva generación entre la Unión Europea y terceros países", LA LEY Unión Europea, núm. 68, marzo-2019.

${ }^{4}$ Como se sabe, los APPRIS intra comunitarios fueron declarados por el TJUE contrarios al Derecho de la UE en el caso Achmea. Por ello, se dejará de lado cualquier análisis o referencia a los APPRIS intracomunitarios.
} 
6. El Tratado de Lisboa supuso una importante consolidación de la política comercial común y de la correspondiente acción exterior de la UE en esta materia [art. 3.1e) TFUE]. Dentro de este pilar, la UE solo tiene competencia exclusiva en materia de inversiones extranjeras directas (207 TFUE). ${ }^{5}$ Por ello, como se deriva del Dictamen 2/15 del TJUE de 16 de mayo de 2017 relativo al Acuerdo de Libre Comercio entre la Unión Europea y la República de Singapur, la UE solo tiene competencia para celebrar tratados internacionales en el ámbito de su acción exterior en relación con este tipo de inversiones. En cuanto a las inversiones distintas de las directas, en la medida en que estas pueden suponer un movimiento de capitales dentro del espacio comunitario, existe una competencia compartida entre la UE y sus EE. MM. [art. 4.2 a) TFUE]. ${ }^{6}$

7. La delimitación competencial supone que aquellos tratados de libre comercio que incluyan la protección de inversiones extranjeras directas e indirectas deban ser celebrados por la UE y los distintos EE. MM. A este tipo de tratados se los denomina acuerdos mixtos.

8. En cuanto a la competencia de la UE en relación con el sistema de resolución de controversias en materia de inversiones extranjeras, el TJUE considera que es objeto de una competencia compartida, ya que «un régimen de esta índole, que sustrae diferencias a la competencia jurisdiccional de los Estados miembros, no puede tener carácter meramente auxiliar [...] y, en consecuencia, no puede establecerse sin el consentimiento de éstos»?

9. En definitiva, la política comercial común y la correspondiente acción exterior de la UE —en la que «sustituye a sus Estados miembros»" — ha supuesto que en materia de protección de inversiones extranjeras existan una serie de competencias compartidas. La atribución de competencia en materia de inversiones a la UE ha supuesto, a su vez, un desplazamiento al TJUE de una parte del control institucional del arbitraje de inversiones.

10. Esta dualidad de competencias supone que los sistemas de protección de inversiones deban aprobarse por la UE (art. 218 TFUE) y por los distintos EE. MM. a través de sus respectivos procedimientos constitucionales (los arts. 93 a $96 \mathrm{CE}$ ) y que su adecuación con los ordenamientos comunitario

\footnotetext{
${ }^{5}$ Dictamen 2/15 del Tribunal de Justicia (Pleno) de 16 de mayo de 2017 [Acuerdo de Libre Comercio entre la Unión Europea y la República de Singapur]: «las inversiones directas, es jurisprudencia reiterada que éstas consisten en cualquier tipo de inversión efectuada por personas físicas o jurídicas que sirva para crear o mantener relaciones duraderas y directas entre el proveedor de fondos y la empresa a la que se destinan dichos fondos para el ejercicio de una actividad económica. La adquisición de participaciones en una empresa constituida en forma de sociedad por acciones es una inversión directa cuando las acciones que posee el accionista le ofrecen la posibilidad de participar de manera efectiva en la gestión o el control de dicha sociedad [...] las inversiones extranjeras distintas de las directas pueden, en particular, realizarse en forma de adquisiciones de títulos societarios con el objetivo de llevar a cabo una inversión de capital sin intención de influir en la gestión y el control de la empresa (inversiones «de cartera») y que tales inversiones constituyen movimientos de capitales en el sentido del artículo 63 TFUE».

${ }^{6}$ Dictamen 2/15 del Tribunal de Justicia (Pleno) de 16 de mayo de 2017 p. 227-256. Al respecto, vid. I. IrURETAGOIENA AgirRezabalaga, "El capítulo sobre inversiones del Acuerdo Económico y Comercial Global de la Unión Europea y Canadá (CETA): análisis crítico de una iniciativa inacabada” en Arbitraje, vol. X, n 1, 2017, pp. 44-51; o J. C. FERnÁndEz RozAS, "Permanencia y expansión del bilateralismo", op. cit. Esta dualidad de competencias también supone que tanto la UE como los distintos EE MM ostenten legitimación pasiva en el arbitraje de inversiones. Con el fin de establecer las reglas para coordinar su actuación en el sistema de resolución de controversias y la responsabilidad financiera derivada de los laudos se dictó el Reglamento (UE) no 912/2014 del Parlamento Europeo y del Consejo de 23 de julio de 2014 por el que se establece un marco para gestionar la responsabilidad financiera relacionada con los tribunales de resolución de litigios entre inversores y Estados establecidos por acuerdos internacionales en los que la Unión Europea sea parte.

${ }^{7}$ Dictamen 2/15 del Tribunal de Justicia (Pleno) de 16 de mayo de 2017: «[e]1 Tribunal de Justicia ya ha tenido la ocasión de señalar que la competencia de la Unión para contraer compromisos internacionales incluye la de acompañar esos compromisos de disposiciones institucionales. Su presencia en el acuerdo no influye en la naturaleza de la competencia para celebrarlo. En efecto, esas disposiciones tienen carácter auxiliar y se encuadran, pues, en la misma competencia que la correspondiente a las disposiciones sustantivas a las que acompañan [...] Pues bien, un régimen de esta índole, que sustrae diferencias a la competencia jurisdiccional de los Estados miembros, no puede tener carácter meramente auxiliar en el sentido de la jurisprudencia recordada en el apartado 276 del presente dictamen, y, en consecuencia, no puede establecerse sin el consentimiento de éstos».

${ }^{8}$ Dictamen 2/15 del Tribunal de Justicia (Pleno) de 16 de mayo de 2017, p. 248.
} 
y nacionales pueda ser controlada de forma previa por el TJUE (art. 218.11 TFUE) y, en su caso, por los correspondientes tribunales constitucionales (arts. 96 CE y 78 LOTC). Además, y en relación con lo que ahora centra nuestra atención, exige que el sistema de arbitraje de inversiones deba ser compatible tanto con el art. 47 de la CDFUE como con el art. 24 CE.

\subsection{Un cambio de modelo}

11. El mecanismo de resolución de diferencias entre los Estados y los inversores extranjeros en los tratados de libre comercio de nueva generación supone un cambio de modelo en el sistema. La intención de la UE es que la progresiva celebración de estos tratados sustituya a los distintos APPRIS de los EE. MM. con terceros países. En cuanto al sistema arbitral propiamente dicho, el cambio de modelo se materializa en la creación de «tribunales» permanentes y en la exclusión del efecto directo de los tratados.

12. Aunque la cantidad de APPRIS en vigor entre España y terceros Estados impide hacer afirmaciones categóricas, la realidad es que la mayoría de ellos contiene una estructura y contenido similar. ${ }^{9}$ Una vez tramitado conforme al procedimiento constitucional, el APPRI se incorpora al ordenamiento jurídico interno y tiene eficacia directa (art. $96 \mathrm{CE}$ ). Esto supone que pueda ser alegado directamente por los inversores ante los órganos judiciales españoles. ${ }^{10}$ De esta manera, los derechos o intereses materiales reconocidos a particulares que tengan su fundamento en el tratado internacional — treaty claimsson tutelables ante la jurisdicción ordinaria. ${ }^{11}$

13. Además de lo anterior, y en ello reside el verdadero interés de los APPRIS, los inversores tienen la posibilidad de someter la resolución de sus controversias a un sistema de arbitraje internacional. Según lo que determine el APPRI, el arbitraje puede desarrollarse en el seno de distintas organizaciones o instituciones arbitrales internacionales. Entre ellas, el Centro Internacional de Arreglo de Diferencias creado por el Convenio sobre arreglo de diferencias relativa a inversiones entre Estados y nacionales de otros Estados (CIADI) — del que España es parte desde 1994-. También es usual que se permita someter la resolución de la controversia a un tribunal arbitral «ad hoc» establecido conforme a las reglas del Reglamento de arbitraje de la CNUDMI. ${ }^{12}$

14. El arbitraje constituye así una alternativa puesta al alcance del inversor extranjero. Para acceder a ella es necesario que el inversor manifieste su consentimiento al arbitraje y, en algunos casos, renuncie a cualquier acción ejercitada o susceptible de ser ejercitada ante los tribunales judiciales nacionales. ${ }^{13}$

\footnotetext{
${ }^{9}$ La lista y texto de los APPRIS en vigor está disponible en http://www.comercio.es/es-ES/inversiones-exteriores/acuerdos-internacionales/acuerdos-promocion-proteccion-reciproca-inversiones-appris/Paginas/lista-appri-vigor.aspx

${ }^{10}$ «Tradicionalmente, los APPRI han presentado la opción del arbitraje junto al de los tribunales internos del estado cuya responsabilidad se reclama; de este modo, ha sido el inversor quien, ante el surgimiento de una controversia, ha optado por iniciar la vía judicial o arbitral. Incluso en los casos en los que un APPRI no hubiera previsto la vía judicial interna, esta debía entenderse abierta para el inversor, en la medida en que el arbitraje no se considera "obligatorio" para este» (I. IRURETAGOIENA AgirRezabalaga, "El capítulo sobre inversiones", op. cit., p. 87). «Los acuerdos españoles de segunda generación, en línea con la práctica más tradicional, conceden al inversor extranjero la facultad de seleccionar el foro jurisdiccional entre los tribunales internos del Estado receptor y los Tribunales arbitrales constituidos ad hoc conforme a las reglas bien de la CNUDMI, o bien del CIADI. [...] el APPRI faculta a las partes para convenir el foro competente, otorgando al inversor la última palabra en cuanto a su elección» (F. J. PASCUAL VIVES, "El arbitraje de inversiones en los recientes APPRI españoles", Revista Electrónica de Estudios Internacionales, núm. 18, pp. 17-18).

${ }^{11}$ Los derechos o intereses objeto de tutela del inversor extranjero pueden tener su origen en una relación contractual con el Estado - contractual claims - en la legislación ordinaria o en el tratado internacional — treaty claims —. En todo momento nos centraremos en estas últimas.

${ }^{12}$ B. Hess, The Private-Public Law Divide in International Dispute Resolution, Brill, 2018, pp. 136-148.

${ }^{13}$ En este sentido v.gr. el art. 10.5 del Acuerdo para la promoción y protección recíproca de inversiones entre el Reino de España y los Estados Unidos Mexicanos, hecho en México el 10 de octubre de 2006: «[u]n inversor contendiente podrá someter una reclamación a arbitraje únicamente si: a) el inversor manifiesta su consentimiento al arbitraje conforme a los procedimientos establecidos en esta Sección; y b) el inversor renuncia a su derecho de iniciar o continuar cualquier procedimiento ante un tribunal administrativo o judicial de conformidad con la legislación de una Parte Contratante».
} 
15. El consentimiento del Estado de someterse a arbitraje se plasma en el propio tratado internacional y el del inversor extranjero en el correspondiente consentimiento escrito exigible conforme a las normas del Convenio CIADI o el Reglamento de la CNUDMI. ${ }^{14}$ La renuncia al ejercicio de acciones judiciales pretende excluir la existencia de procedimientos paralelos sobre el mismo objeto y así asegurar la denominada eficacia negativa o excluyente del procedimiento arbitral. ${ }^{15}$

16. Los arbitrajes de inversiones incluidos en los tratados de libre comercio de nueva generación suponen un cambio de modelo. Para corroborarlo puede utilizarse como referencia el CETA -recuérdese, con Canadá- que, como consecuencia del Dictamen 1/17, se ha considerado como un golden standard o blue print para la negociación de los futuros acuerdos. ${ }^{16}$

17. El CETA crea un «tribunal» permanente formado por 15 «miembros del tribunal» por un periodo de 5 años renovables que son nombrados por un Comité Mixto. Estos conocerán de la solución de diferencias en materia de inversiones entre inversores y Estados al amparo del Tratado (art. 8.27 CETA). Además, se crea un «tribunal de apelación» que podrá confirmar, modificar o revocar el «laudo» dictado en primera instancia (art. 8.28 CETA).

18. Aunque el CETA y los demás tratados de libre comercio proyectados crean distintos «tribunales» permanentes, la intención de la Comisión Europea es que en un futuro se cree un «tribunal multilateral sobre inversiones». ${ }^{17}$ De esta manera, se concentrarían en un solo «tribunal» las distintas controversias que fueran surgiendo a raíz de los distintos tratados de inversiones.

19. Desde una perspectiva predominantemente política, este sistema de «tribunales» permanentes pretende superar las críticas a las que ha estado sometido el sistema de arbitraje en materia de inversiones extranjeras en los últimos años por parte de la sociedad civil: la falta de transparencia del procedimiento y el sometimiento de las controversias a una «élite» de árbitros alineados con los intereses de los inversores. ${ }^{18}$ Para superar estas críticas se crea un «tribunal» estable que asegure la independencia e imparcialidad de los «miembros del tribunal» elegidos por las partes contratantes —en el caso del CETA, en el seno del Comité Mixto- ${ }^{19}$

${ }^{14}$ B. Hess, The Private-Public Law Divide, op. cit., p. 144. En este sentido, el art. 25 de CIADI «[1]a jurisdicción del Centro se extenderá a las diferencias de naturaleza jurídica que surjan directamente de una inversión entre un Estado Contratante (o cualquiera subdivisión política u organismo público de un Estado Contratante acreditados ante el Centro por dicho Estado) y el nacional de otro Estado Contratante y que las partes hayan consentido por escrito en someter al Centro. El consentimiento dado por las partes no podrá ser unilateralmente retirado» (énfasis añadido).

${ }^{15}$ En abstracto los APPRI pueden permitir o incluso exigir que el inversor agote los recursos judiciales internos (art. 26 CIADI). Sobre el riesgo de procedimientos paralelos vid. G. BotTinI, "Investment Arbitration and Proceedings before Local Courts» en Investment Arbitration Outlook, Uría Menéndez, Issue 1, 2017; también F. J. PAscual Vives, "El arbitraje de inversiones", op. cit., pp. 20-23.

${ }^{16}$ Para un panorama general de la política exterior común de la UE y el proceso de negociación de futuros tratados de libre comercio de nueva generación vid. Informe de la Comisión al Parlamento Europeo, al Consejo, al Comité Económico y Social Europeo y al Comité de las Regiones sobre la aplicación de los Acuerdos de Libre Comercio 1 de enero de 2018 - 31 de diciembre de 2018 [COM/2019/455 final]. Disponible en: https://eur-lex.europa.eu/legal-content/ES/TXT/?uri=CELEX:52019DC0455. También J. C. FernÁNDEZ RozAS, "Permanencia y expansión del bilateralismo", op. cit.

${ }^{17}$ «Directrices de negociación para un Convenio relativo al establecimiento de un tribunal multilateral para la solución de diferencias en materia de inversiones» Disponible en: http://data.consilium.europa.eu/doc/document/ST-12981-2017-ADD-1-DCL-1/ es/pdf Este documento tiene su antecedente en la Recomendación de la Comisión al Consejo «por el que se autoriza la apertura de negociaciones sobre un Convenio relativo al establecimiento de un tribunal multilateral para la solución de diferencias en materia de inversiones» Disponible en: https:/ec.europa.eu/transparency/regdoc/rep/1/2017/ES/COM-2017-493-F1-ES-MAIN-PART-1. PDF En este contexto, se incluyó en el CETA el art. 8.29 conforme al cual: «[1]as Partes perseguirán, junto con otros socios comerciales, la creación de un tribunal multilateral sobre inversiones y de un mecanismo de apelación para la solución de diferencias en materia de inversiones. Al crear tal mecanismo multilateral, el Comité Mixto del CETA adoptará una decisión por la que se establezca que las diferencias en materia de inversiones con arreglo a la presente sección se decidirán con arreglo al mecanismo multilateral, y formulará las disposiciones transitorias oportunas». También se plasma esta intención en el Instrumento interpretativo conjunto sobre el Acuerdo Económico y Comercial Global (AECG) entre Canadá y la Unión Europea y sus Estados miembros.

18 B. Hess, The Private-Public Law Divide, op. cit., pp. 146-148.

19 I. Iruretagoiena Agirrezabalaga, "El capítulo sobre inversiones", op. cit., pp. 79-82. 
20. Junto con esta motivación política, existe una razón técnica de especial interés: la UE no puede formar parte del Convenio CIADI y de aquellos otros tratados internacionales en los que solo se permita la adhesión de «Estados». ${ }^{20}$ Con el modelo diseñado, a través de una peculiar ingeniería jurídica se crea una estructura que permite a la UE formar parte de la operativa actual del arbitraje internacional de inversiones.

21. Además de lo anterior, el segundo gran cambio es la imposibilidad de ejercitar acciones fundadas en el Tratado - treaty claims - ante la jurisdicción ordinaria de cualquiera de las partes contratantes. Según el art. 30.6 de CETA «[n]inguna disposición del presente Acuerdo se interpretará en el sentido de que conceda derechos o imponga obligaciones a personas, distintos de los creados entre las Partes en virtud del Derecho internacional público, ni en el sentido de que el presente Acuerdo pueda invocarse directamente en los ordenamientos jurídicos internos de las Partes».

22. Se excluye así de plano el efecto directo del Tratado en los ordenamientos jurídicos internos, lo que impide que los derechos y obligaciones de los individuos que nazcan del Tratado sean tutelados por los órganos judiciales nacionales. ${ }^{21}$ Esta falta de efecto directo se construye de forma un tanto artificial declarando que el Tratado no concede derechos materiales a los particulares. La realidad, sin embargo, parece ser algo distinta.

23. El Tratado reconoce derechos materiales a los particulares $y$, de hecho, son estos el fundamento de la solicitud de condena al Estado ante el «tribunal» permanente. El propio art. 8.18 CETA sostiene que «un inversor de una Parte podrá presentar al tribunal constituido conforme a la presente sección una denuncia de que la otra Parte ha incumplido una obligación». Aunque la posición activa y pasiva de estas obligaciones y la relación sinalagmática la ocupan los Estados parte, con base en el incumplimiento de estas el inversor podrá pretender y el laudo conceder una «indemnización pecuniaria» o la «restitución de la propiedad» (art. 8.39 CETA).

24. El incumplimiento de las obligaciones estatales hace nacer en el inversor el derecho a exigir una indemnización pecuniaria y determinados efectos restitutorios. No hacen faltan mayores consideraciones dogmáticas para llegar a la conclusión de que el Tratado reconoce derechos materiales al individuo que son la causa de pedir de la condena que se pretende ante el «tribunal» permanente: un derecho de resarcimiento como consecuencia del incumplimiento por parte del Estado de sus obligaciones internacionales. Cuestión distinta es que este derecho material derivado de la responsabilidad patrimonial (internacional) del Estado no pueda ser tutelado por los órganos judiciales nacionales.

25. Esto supone que la única vía que tiene el inversor para ejercitar sus pretensiones basadas en el Tratado sea el «tribunal» permanente. Formalmente se sigue exigiendo el consentimiento del parti-

${ }^{20}$ «The idea that the ICS envisaged by the EU should be regarded as providing Access to ICSID arbitration also raises an important additional ratione personae issue, stemming from the fact that the EU is not a Contracting Party to the ICSID Convention [...] However, for the EU to become a Contracting Party to the ICSID Convention a revision of the Convention would be necessary since Article 67 restricts membership to states (and even more particularly to member States of the World Bank or at least parties to the ICJ Statute). The most straightforward avenue to enable the EU becoming an ICSID Contracting Party would entail the cumbersome treaty amendment procedure under Articles 65 and 66, basically requiring unanimous approval of all existing ICSID Contracting Parties» (A. REINISCH, "Will the EU's Proposal Concerning an Investment Court System for CETA and TTIP Lead to Enforceable Awards?-The Limits of Modifying the ICSID Convention and the Nature of Investment Arbitration", Journal of International Economic Law, 2016, núm. 19, p. 762).

${ }^{21}$ Conclusiones del Abogado General de 29 de enero de 2019 al Dictamen 1/17, p. 63. En relación con ello se ha dicho que el tratado «conduce a rechazar la posibilidad de reclamar los derechos reconocidos en el CETA en los tribunales internos del estado. Solo cabría reclamar ante el Sistema de Tribunales de Inversión y solo por la violación de aquellos derechos que abren la vía del ISDS. Esta conclusión aleja al sistema ISDS del CETA de la lógica que ha guiado desde sus orígenes la solución de diferencias entre inversores y estados, como mecanismo alternativo a los tribunales internos del estado autor del daño» (I. IRURETAGOIENA AGIRREZABALAGA, "El capítulo sobre inversiones", op. cit., pp. 87-88). La exclusión del efecto directo técnicamente permite centralizar la resolución de los conflictos derivados del tratado en un único órgano (en relación con esto, vid. C. VAJDA, "The EU and Beyond: Dispute Resolution in International Economic Agreements”, The European Journal of International Law, Vol. 29 no. 1). 
cular para acceder al «tribunal» (art. 8.22 CETA). Sin embargo, realmente este es el único medio que tiene para hacer valer los derechos - $\mathrm{o}$ si se prefiere, para adecuarse a la idea que pretende trasladar el CETA, sus «expectativas» económicas- En la medida en que no existe otra vía para hacer valer las reclamaciones nacidas del tratado - treaty claims - , desaparece toda alternativa razonable al arbitraje de inversiones.

26. Lo anterior lleva a concluir de forma irremediable que en relación con las reclamaciones que tengan su origen en el tratado se ha creado o una jurisdicción internacional con competencia exclusiva o un arbitraje obligatorio. ${ }^{22}$

27. En este sentido se enmarca la afirmación del TJUE en relación con el acuerdo de libre comercio UE-Singapur — sustancialmente idéntico al CETA—: un régimen de esta índole «sustrae diferencias a la competencia jurisdiccional de los Estados miembros». La diferencia en el nuevo modelo es que esta sustracción de la competencia jurisdiccional es impuesta al inversor, ya que solo ante el «tribunal» permanente podrán pretenderse sus reclamaciones pecuniarias o de otro tipo que nazcan del Tratado.

28. Además, el CETA también impone como requisito para acceder al «tribunal» que el individuo renuncie «a su derecho a iniciar una demanda o un procedimiento ante un tribunal u órgano jurisdiccional con arreglo al Derecho interno o internacional respecto a una medida que supuestamente constituya una infracción mencionada en su denuncia» (art. 8.22 CETA). En la medida en que no hay forma de pretender reclamaciones con base en el tratado ante los órganos judiciales nacionales, es razonable concluir que lo que el tratado impone no es la renuncia de acciones judiciales con origen en este - algo lógico y coherente para evitar procedimientos paralelos, aunque aquí innecesario por imposible-, sino la renuncia al ejercicio de cualquier otra acción eventualmente basada en el Derecho nacional cuya causa de pedir la constituyan los mismos hechos. ${ }^{23}$

\section{La compatibilidad del sistema de solución de diferencias en materia de inversiones con el Art. 47 CDFUE}

29. Dicho lo anterior, es oportuno hacer una exposición de la compatibilidad del sistema de solución de diferencias en materia de inversiones con el art. 47 CDFUE, partiendo para ello del Dictamen 1/17 del TJUE. El Dictamen es de interés por cuanto, por un lado, permite sentar las bases de la dimensión objetiva de los derechos fundamentales en el ordenamiento comunitario y su proyección en el ámbito de la acción exterior de la UE y, por otro, por suponer un juicio de la compatibilidad del sistema de solución de diferencias del CETA con el referido art. 47 CDFUE.

\footnotetext{
22 «Their jurisdiction, moreover, is compulsory not only for the respondent, but also for the claimant investor: the only forum where a CETA claim can be brought is the CETA adjudicative machinery» (V. FerReres Comella, "The European Court of Justice Rules on CETA's Investor-State Dispute Resolution Mechanism”, Investment Arbitration Outlook, Uría Menendez, 2019, Issue 5, p. 10). Por eso este sistema se convierte «en la única vía para hacer valer el nivel de protección sustantivo otorgado en dichos Acuerdos [...] El sistema de tribunales internacionales de inversión tiene carácter obligatorio para ambas partes, desde el momento en que el inversor quiera hacer valer directamente las disposiciones del CETA o las de cualquier otro Acuerdo donde se contemple el mismo» (E. Fernández Masiá, M. Salvadori, "Lo que se está discutiendo en la CNUDMI: evolución o revolución en el sistema de solución de controversias inversor-Estado", Cuadernos de Derecho Transnacional, (Marzo 2020), Vol. 12, No 1, p. 214).

${ }^{23}$ CETA Art. 8.22: «1. Un inversor solo podrá presentar una demanda de conformidad con el artículo 8.23 si el inversor: $[\ldots] \mathrm{g})$ renuncia a su derecho a iniciar una demanda o un procedimiento ante un tribunal u órgano jurisdiccional con arreglo al Derecho interno o internacional respecto a una medida que supuestamente constituya una infracción mencionada en su denuncia». Por eso se ha defendido que «Obwohl der Verzicht zur Durchführung künftiger nationaler Gerichtsverfahren unter bestimmten Voraussetzungen unwirksam ist (Art. 8.22 Abs. 5 CETA), würde die Wahl des Rechtswegs vor das CETA-Gericht faktisch einen Verzicht auf die Geltendmachung eines Verstoßes gegen nationales Recht bedeuten» (SCHILL "Investitionsschutz in EU-Freihandelsabkommen: Erosion gesetzgeberischer Gestaltungsmacht?”, Zä̈RV, 2018, 33, p. 76).
} 


\subsection{La externalización y dimensión objetiva del art. 47 CDFUE}

30. Como afirma el TJUE, el «tribunal» permanente del CETA «se encuentra fuera del sistema jurisdiccional de la Unión» formado por los distintos órganos judiciales nacionales que están llamado a aplicar el Derecho de la UE y por el TJUE como último intérprete y guardián del ordenamiento comunitario (art. 19 TUE). En definitiva, «la jurisdicción prevista por el CETA es distinta de la de los órganos jurisdiccionales internos». ${ }^{24}$

31. El hecho de que el «sistema de tribunales» creado por el CETA esté fuera de la arquitectura judicial de la UE supone que en su seno no sea materialmente aplicable la CDFUE (art. 51). Por lo tanto, es imposible que el «tribunal permanente» vulnere el art. 47 CDFUE: no existe ninguna vinculación de este a la Carta.

32. No obstante, el Tribunal recuerda que «los acuerdos internacionales celebrados por la Unión deben ser plenamente compatibles con los Tratados y con los principios constitucionales», por lo que se debe exigir «la compatibilidad de un acuerdo internacional previsto con las garantías establecidas en la Carta, que tiene el mismo valor jurídico que los Tratados». Por ello «al celebrar un acuerdo internacional que incluya la creación de órganos que tengan características judiciales predominantes y que estén destinados a resolver diferencias, en particular entre inversores privados y Estados [...] la Unión está sujeta, respecto al modo de acceso a estos órganos y a la independencia de estos, a lo dispuesto en el artículo 47, párrafos segundo y tercero, de la Carta». Esto supone que la Unión no podría «celebrar un acuerdo que establezca tribunales competentes para dictar laudos obligatorios para la Unión y para tratar diferencias planteadas ante ellos por justiciables de la Unión sin que se les ofrezcan dichas garantías». ${ }^{25}$ Así, el Tribunal proyecta la dimensión objetiva de los derechos fundamentales reconocidos en la Carta a cualquier actuación de la UE, incluida su acción exterior. ${ }^{26}$

33. Esto supone una externalización o proyección objetiva de las garantías del art. 47 CDFUE ad extra - Externalisierung der Unionsgrundrechte-.${ }^{27}$ En estos casos, el art. 47 CDFUE no es materialmente aplicable (art. 51 CDFUE), por lo que el derecho fundamental no despliega ninguna eficacia subjetiva. Sin embargo, la vinculación de la UE a la Carta exige que las garantías institucionales y de procedimiento del art. 47 CDFUE se incorporen en los mecanismos internacionales de resolución de controversias en los que pueda intervenir un particular. ${ }^{28}$

${ }^{24}$ Dictamen 1/17 del Tribunal de Justicia (Pleno) de 30 de abril de 2019, pp. 106-114.

${ }^{25}$ Dictamen 1/17 del Tribunal de Justicia (Pleno) de 30 de abril de 2019, pp. 189-198.

${ }^{26}$ S. Stöbener de Mora, S. Wernicke, "Riskante Vorgaben für Investitionsschutz", op. cit., p. 975.

27 «Schließlich ergeben sich aus dem CETA-Gutachten unionsgrundrechtliche Anforderungen für internationale Gerichte. Danach darf sich die Union nicht an der Errichtung eines internationalen Gerichts beteiligen, das über Klagen von Unionsbürgerinnen und bürgern entscheidet, ohne dass die Garantien des Unionsrechts gewahrt werden [...] Das CETA-Gutachten geht nun einen entscheidenden Schritt weiter, indem es die volle Beachtung der unionsinternen Standards für die Rechtsschutzgewährung durch internationale Gerichte verlangt: Die Investitionsgerichte müssten die Anforderungen von Art. 47 Abs. 2 und 3 GRCh vollumfänglich wahren. [...] Das CETA-Gutachten aber wendet den vollen Grundrechtsstandard erstmals auf ein in- ternationales Gericht an» (H. SAUER, "Europarechtliche Schranken internationaler Gerichte", JZ, 2019, núm. 74, p. 928). La Comisión ha señalado igualmente que «[L]a Unión se basará en los principios de la democracia, el Estado de Derecho, los derechos humanos y las libertades fundamentales en lo relativo a esta iniciativa, incluido en particular el artículo 47 de la Carta de los Derechos Fundamentales. La acción de la Unión en el ámbito multilateral no puede afectar al nivel de protección de los derechos fundamentales en la Unión» (Recomendación de la Comisión al Consejo por la que se autoriza la apertura de negociaciones sobre un Convenio relativo al establecimiento de un tribunal multilateral para la solución de diferencias en materia de inversiones, p. 6).

${ }^{28}$ La preocupación por la compatibilidad de estos nuevos tribunales permanentes con las garantías procesales reconocidas por los distintos sistemas de derechos fundamentales nacionales e internacionales se constata en la Resolución de la $18^{\circ}$ Comisión del Instituto de Derecho Internacional de 28 de agosto de 2019 «Equality of Parties before International Investment Tribunals». 


\subsection{La compatibilidad del CETA con el art. 47 CDFUE}

34. En relación con el concreto sistema de resolución de controversias del CETA, el TJUE aprecia de forma correcta que la falta de efecto directo del tratado supone el «carácter obligatorio de la competencia de esos tribunales» ya que «dicha competencia se impondrá no solamente al demandado, que deberá aceptarla en virtud del artículo 8.25 del CETA, sino también al inversor demandante, en el supuesto de que este pretenda invocar directamente las disposiciones del CETA. En efecto, puesto que el artículo 30.6 del CETA priva a los inversores de la posibilidad de invocar directamente este Acuerdo ante los órganos jurisdiccionales internos de las Partes, toda acción basada directamente en las disposiciones de ese Acuerdo deberá ejercitarse ante el Tribunal del CETA». ${ }^{29}$

35. Expuesto lo anterior, y una vez sentadas las bases para justificar la exigencia de compatibilidad del tratado con la CDFUE, el TJUE analiza si el «tribunal» permanente con competencia obligatoria creado por el CETA cumple con las garantías del art. 47 CDFUE. En concreto, el TJUE se centra en las garantías de imparcialidad e independencia de los «miembros del tribunal» y en el acceso de todos los justiciables a este.

36. En apretado resumen, el TJUE considera que se cumplen las garantías de independencia e imparcialidad que impone el art. 47 CDFUE por cuanto los «miembros del tribunal» ejercen sus funciones con plena autonomía: son nombrados por un periodo de 5 años renovable por una vez, su destitución se limita a supuestos concretos de incumplimientos determinados en el tratado, reciben una retribución adecuada a sus funciones que con la consolidación de la actividad del «tribunal» aspira a convertirse en fija, entre otras cuestiones. En relación con la posibilidad de que el Comité Mixto creado por el CETA dicte interpretaciones vinculantes para el «tribunal» (art. 8.31 CETA), el TJUE considera que el art. 47 CDFUE impide que estas interpretaciones tengan efectos sobre asuntos resueltos o pendientes. Y aunque «esta garantía de falta de efecto retroactivo y de efecto inmediato sobre los asuntos pendientes no esté prevista expresamente» en el CETA, el TJUE considera que en la medida en que la Carta vincula a la UE en toda su actuación, también lo hará cuando esta participe en el Comité Mixto del CETA. Por lo que la proyección objetiva del art. 47 CDFUE no «autoriza a la Unión a aceptar decisiones de interpretación del Comité Mixto del CETA que produzcan efectos sobre el trato de las diferencias ya resueltas o pendientes». ${ }^{30}$

37. En relación con el derecho de acceso a la justicia del art. 47 CDFUE el TJUE considera que, aunque el sistema "podría resultar, en la práctica, accesible exclusivamente a los inversores que dispongan de importantes recursos financieros», la UE se ha comprometido (Declaración $n^{\circ} 36$ ) a asegurar el acceso a este «nuevo órgano jurisdiccional para los usuarios más vulnerables». En la medida en que el objeto de enjuiciamiento se proyecta sobre un acuerdo internacional previsto (art. 218 TFUE), para el TJUE este compromiso «basta para llegar a la conclusión de que el CETA [...] es compatible con la exigencia de accesibilidad a dichos tribunales». ${ }^{31}$

38. Sin entrar a comentar críticamente las valoraciones del TJUE, una vez proyectadas objetivamente las garantías del art. 47 CDFUE, este llega a la conclusión de que el CETA es en este punto compatible con la Carta.

\section{La solución de diferencias en materia de inversiones: ¿tribunal o arbitraje internacional?}

39. Antes de analizar la compatibilidad del sistema del CETA expuesto con nuestro sistema interno de garantías procesales — esto es, con el art. $24 \mathrm{CE}$ - es oportuno hacer una referencia a la con-

\footnotetext{
${ }^{29}$ Dictamen 1/17 del Tribunal de Justicia (Pleno) de 30 de abril de 2019, p. 198.

${ }^{30}$ Dictamen 1/17 del Tribunal de Justicia (Pleno) de 30 de abril de 2019, pp. 223-224.

${ }^{31}$ Dictamen 1/17 del Tribunal de Justicia (Pleno) de 30 de abril de 2019, pp. 222-205.
} 
creta naturaleza del «tribunal» permanente diseñado. Esta es una cuestión que puede tener incidencia directa en el anclaje constitucional de estos «tribunales» permanentes en nuestro ordenamiento.

40. Se debe ser consciente de que el sistema que se analiza supone un nuevo modelo que impide una identificación exacta con las categorías prexistentes con las que se suele operar. Como se ha dicho ya, el tradicional arbitraje de inversiones ha supuesto una ruptura de la rígida separación entre el Derecho internacional y el Derecho privado. ${ }^{32} \mathrm{El}$ reconocimiento de derechos e intereses materiales con fundamento en la responsabilidad internacional del Estado tutelables por los órganos judiciales nacionales - en aquellos tratados con efecto directo- y por instituciones arbitrales internacionales supone una expansión de la aplicación de los tratados internacionales y la consolidación del individuo como un operador más en los sistemas internacionales de resolución de controversias. ${ }^{33}$

41. En el CETA, y en los demás textos convencionales en proceso de negociación, parecen utilizarse algunos términos con intencionada ambigüedad. ${ }^{34}$ Como se ha dicho, una de las intenciones de la nueva policía comercial común de la UE es la creación de «tribunales» permanentes que superen las críticas vertidas contra los existentes creando, en palabras de la Comisión, un «sistema jurisdiccional institucionalizado». ${ }^{35}$ El léxico utilizado en los textos convencionales pretende consolidar esta idea de «institucionalización». Sin embargo, es razonable cuestionarse si este cambio en los términos supone realmente una transformación de la naturaleza de los órganos encargados de resolver el conflicto y del sistema en sí.

42. En función de la naturaleza que del «tribunal» permanente se predique se llegará a una u otra conclusión: el nuevo sistema crea tribunales internacionales con jurisdicción sobre individuos o un arbitraje internacional obligatorio. En función de la respuesta, a su vez, deberá ponerse el foco en el proceso de aprobación del tratado (art. $93 \mathrm{CE}$ ) y en la forma en que el derecho a la tutela judicial efectiva se proyecta objetivamente sobre la actuación exterior del Estado español en la creación de tribunales internacionales en los que puedan intervenir particulares o en la compatibilidad del arbitraje obligatorio con el derecho a la tutela judicial efectiva de los inversores — españoles y extranjeros- (art. $24 \mathrm{CE}$ ).

Es de interés constatar cómo las dudas en torno a la naturaleza de «tribunales» internacionales permanentes como el que aquí se analiza ya fueron objeto de discusión hace más de 100 años. El Tratado de Versalles creó, al término de la Primera Guerra Mundial, una serie de tribunales arbitrales mixtos que conocían de reclamaciones pecuniarias de particulares frente a las potencias vencidas. Estas estaban relacionadas con la expropiación y expolio de su patrimonio durante el conflicto bélico. El sistema de tribunales mixtos y la posibilidad de que los particulares pudieran acceder a ellos supuso una auténtica novedad en su época. ${ }^{36}$

\footnotetext{
${ }^{32}$ B. Hess, The Private-Public Law Divide, op. cit., pp. 21-41, 277.

33 «[L]as nuevas dimensiones abiertas por los acuerdos bilaterales de protección de inversiones (APPRIS) y los arbitrajes que se basan en ellos, pues entre otras cosas amplían el ius standi de los particulares y les proporcionan un cauce jurisdiccional internacional para resolver sus controversias con el Estado» (P. ANDRÉs SÁEnZ dE SANTA MARÍA, Sistema de Derecho Internacional Público, Civitas, $4^{\text {a }}$ ed., Madrid, 2016 [capítulo VII apartado IV]).

${ }^{34}$ A. ReINISCH, "Will the EU's Proposal Concerning an Investment Court System", op. cit., p. 765.

${ }^{35}$ Recomendación de la Comisión al Consejo por la que se autoriza la apertura de negociaciones sobre un Convenio relativo al establecimiento de un tribunal multilateral para la solución de diferencias en materia de inversiones, p. 3.

36 "The Allied and Associated Powers did not entrust the German, Austrian and Hungarian courts with implementation of the substantive provisions of the peace treaties as they mistrusted the willingness of these courts to fully implement the one-sided regimes of the peace treaties. Under the national applicable jurisdictional rules, these courts were competent to address private law issues regarding assets located on their soil. Instead, the peace treaties established a self-standing court system, the Mixed Arbitral Tribunals [...] The name of these tribunals was due to their international composition: two arbiters were nominated by the respective governments, and a presiding judge was chosen by agreement between the two Governments who was a national of a neutral state. The most prominent and innovative feature of the peace treaties was the standing of individuals before these courts [...] In 1919, the idea of establishing international arbitral tribunals competent for the resolution of disputes between individuals (or individuals against states) at the international level was innovative [...] One of the most debated issues in the literature between the 1920s and the 1930s was the nature of the MATs: Were they national adjudicatory bodies, international ones, or rather a tertium genus? Should they be considered as an exceptional jurisdiction, or as a general one? Scholars addressing the issue of the national or international nature of the MATs reached different con-
} 
Se ha visto por algunos en estos tribunales un peculiar paralelismo e inspiración con los actuales tribunales permanentes en materia de inversiones. ${ }^{37}$

43. Aunque un estudio exhaustivo de la naturaleza de estos tribunales desbordaría por completo la intención de estas líneas, puede ser de interés plantear algunas ideas preliminares que permitan una reflexión ulterior sobre la cuestión. La consolidación del individuo en el sistema internacional de resoluciones de controversias impone la actualización de algunos conceptos nucleares, como los de jurisdicción y potestad jurisdiccional nacional e internacional. ${ }^{38}$

\subsection{El «tribunal» permanente de inversiones: ¿una jurisdicción internacional?}

44. El TJUE sostiene que el arbitraje de inversiones del CETA es un sistema «"híbrido" por presentar, además de características jurisdiccionales, otros aspectos que se basan en los mecanismos tradicionales de arbitraje en materia de inversiones [...] sin que sea necesario dilucidar si las Partes calificarán formalmente a esos tribunales de "órganos jurisdiccionales" [...] se desprende que esos tribunales ejercerán esencialmente funciones judiciales». ${ }^{39}$

45. Como se sabe, la función jurisdiccional supone la aplicación del Derecho objetivo al caso concreto: «decir y hacer el Derecho». ${ }^{40}$ La jurisdicción es el «sistema orgánico e institucional» que lleva a cabo la función jurisdiccional. La potestad jurisdiccional se identifica con el «conjunto de poderes $\mathrm{y}$ atribuciones que tienen los tribunales de justicia para llevar a cabo la función jurisdiccional». ${ }^{41} \mathrm{La}$

clusions depending on what decisive criterion they followed: the origin of the institution, or its function» (M. REQUEJo ISIDRO, B. Hess, "The Mixed Arbitral Tribunals in the Peace Treaties of 1919-1922", MPILux Research Paper Series, 2018 (5), pp. 8, 10, 17. Tambien en "International Adjudication of Private Rights: The Mixed Arbitral Tribunals in the Peace Treaties of 1919-1922" en M. Erpelding, B. Hess, H. Ruiz Fabri, (eds.) Peace Through Law. The Versailles Peace Treaty and Dispute Settlement After World War I, Nomos, Baden-Baden, 2019, pp. 239-276). En el mismo sentido, B. Hess, The Private-Public Law Divide, op. cit., pp. 110-116.

37 «The debate about the legal nature of the MAT recalls the debate about the legal nature of other modern international courts and tribunals deciding on claims of individuals against states and international organizations as the US-Iranian Claims Tribunal, the United Nations Compensation Commission or the Eritrea Ethiopian Claims Commission. The most interesting parallelism relates to investment arbitration [...] The similarities might even increase when permanent investment courts are established» (M. Requejo Isidro, B. Hess, "The Mixed Arbitral”, op. cit., pp. 19-20). Este paralelismo ha supuesto un renovado interés en estos tribunales. Una muestra de lo anterior es el seminario «Mixed Arbitral Tribunals, 1919-1930: An Experiment in the International Adjudication of Private Rights» programado para el 22 y 23 de noviembre de 2020 en el Max Planck Institute Luxembourg for International, European and Regulatory Procedural Law: https://www.mpi.lu/ news-and-events/2020/october/22-23/mixed-arbitral-tribunals-1919-1930-an-experiment-in-the-international-adjudicationof-private-rights/

38 «These proposed changes raise the general question whether such ISDS can still be regarded as ISA or has already migrated into the field of judicial dispute settlement, with the practically highly important effect that its outcomes may have to be considered judgments and not arbitral awards» (A. ReINISCH, "Will the EU's Proposal Concerning an Investment Court System", op. cit., p. 762).

${ }^{39}$ Dictamen 1/17 del Tribunal de Justicia (Pleno) de 30 de abril de 2019 pp. 193-197. Según el Instrumento interpretativo conjunto sobre el Acuerdo Económico y Comercial Global (AECG) entre Canadá y la Unión Europea y sus Estados miembros, el Tribunal permanente: «se aleja firmemente del planteamiento tradicional de la solución de diferencias en materia de inversión y crea tribunales sobre inversiones independientes, permanentes e imparciales, inspirados en los principios de los sistemas judiciales públicos en la Unión Europea y sus Estados miembros y Canadá, así como en los tribunales internacionales como la Corte Internacional de Justicia y el Tribunal Europeo de Derechos Humanos». Según las conclusiones del Abogado General «[e]l modelo adoptado presenta, en varios aspectos, características originales que le confieren un carácter híbrido, suerte de compromiso entre un tribunal arbitral y un órgano jurisdiccional internacional. Por tanto, la vía elegida por la Unión en el marco del CETA consiste en la institucionalización y la judicialización del mecanismo de solución de diferencias en materia de inversiones, reflejo del equilibro entre tradición e innovación en el ámbito del arbitraje de inversión [...] este último régimen, en su estado actual de desarrollo, que se aparta del arbitraje clásico y se aproxima a un sistema jurisdiccional» (Conclusiones del Abogado General de 29 de enero de 2019 al Dictamen 1/17).

${ }^{40}$ F. Gascón Inchausti, Derecho Procesal Civil. Materiales para el estudio, pp. 29-30. Disponible en: https://eprints.ucm. es/56973/1/Derecho\%20Procesal\%20Civil\%20-\%20Fernando\%20Gascon\%20Inchausti\%20-\%202019.pdf

${ }^{41}$ F. Gascón Inchausti, Derecho Procesal Civil, op. cit., p. 28. 
potestad jurisdiccional está íntimamente ligada a la idea de soberanía estatal, por lo que corresponde en exclusiva al Estado y, en concreto, a los órganos judiciales (art. $117 \mathrm{CE}){ }^{42}$

46. Por otro lado, el arbitraje supone una renuncia puntual al ejercicio del derecho a la tutela judicial efectiva (art. $24 \mathrm{CE}$ ): se renuncia a recibir la tutela judicial estatal para someter la resolución de la controversia a un particular. El árbitro, si así lo han querido las partes, interpreta y aplica el Derecho objetivo al caso concreto. En ese sentido, puede considerarse que el árbitro lleva a cabo parte de la función jurisdiccional: dice el Derecho al caso concreto. Sin embargo, desde luego, esto no lo convierte en un órgano judicial dotado de potestad jurisdiccional.

47. El poder del árbitro de dictar una resolución vinculante se basa en la autonomía de la voluntad de las partes plasmada en el convenio arbitral; no emana del conjunto de poderes y atribuciones que, derivados de la soberanía estatal, se atribuyen a los jueces y tribunales (art. $117 \mathrm{CE}$ ). La labor jurisdiccional de los árbitros es llevada a cabo no con base en un poder público atribuido constitucionalmente, sino que tiene su fundamento en la voluntad de las partes.

48. La falta de potestad jurisdiccional impide calificar al árbitro como juez o tribunal, lo que explica - entre otras cosas - la imposibilidad de que los árbitros o tribunales arbitrales planteen cuestiones de inconstitucionalidad ante el TC o cuestiones prejudiciales ante el TJUE. Por eso, como se ha defendido, la denominada «equivalencia jurisdiccional» del arbitraje se predica respecto de sus efectos - la solución de la controversia con efectos de cosa juzgada - , pero no de su naturaleza. ${ }^{43}$ Por ello, la «función esencialmente judicial» que lleve a cabo el «tribunal» permanente del CETA no es un elemento que permita concluir automáticamente que es un órgano jurisdiccional internacional.

49. Aunque un estudio de los conceptos de «tribunal internacional» y de «jurisdicción internacional» está totalmente fuera del alcance de estas líneas, la referida consolidación del individuo en los sistemas internacionales de resolución de conflictos impone hacer una distinción entre aquellos tribunales internacionales que tienen como finalidad resolver controversias entre Estados y aquellos que tienen competencia para conocer de conflictos jurídicos planteados por o frente a individuos.

50. Los tribunales internacionales son el principal sistema para resolver conflictos jurídicos entre Estados soberanos — par in parem non habet imperium - . Estos se fundamentan en la autonomía soberana de los Estados que consienten respecto de un caso concreto o en general respecto de cualquier controversia la decisión adoptada. El poder vinculante de la resolución del tribunal tiene su fundamento en la soberanía estatal plasmada en el tratado internacional que lo crea.

51. Este esquema de igualdad de sujetos soberanos no se reproduce con exactitud en aquellos sistemas en los que pueden intervenir particulares. En este caso, entra en el panorama un individuo dotado de derechos fundamentales reconocidos tanto en el plano del ordenamiento internacional como nacional. ${ }^{44}$

52. Lo anterior supone que el poder de interpretar y aplicar el Derecho internacional respecto de individuos sometidos a la jurisdicción de un Estado soberano solo puede basarse, como en el ordenamiento interno, en una potestad jurisdiccional internacional o en la propia autonomía de la voluntad del individuo.

${ }^{42}$ F. Gascón Inchausti, Derecho Procesal Civil, op. cit., pp. 30, 34.

${ }^{43}$ G. Schumann Barragán, "Comentario a la STC 1/2018 de 11 de enero (Pleno) sobre la inconstitucionalidad del art. 73 e) de la Ley del Contrato de Seguro”, FORO. Revista de Ciencias Jurídicas y Sociales, Nueva Época, 2018, p. 404. Disponible en: https://revistas.ucm.es/index.php/FORO/article/view/61812

${ }^{44}$ La diferencia entre estos dos tipos de tribunales se constata en el Dictamen 1/15 del TJUE. En este se analiza por separado la «solución de diferencias entre un inversor y un Estado» y la «solución de diferencias entre las Partes» firmantes del tratado internacional: la UE y sus EE MM y el tercer país. 
53. Como se sabe, aunque la potestad jurisdiccional emana de la soberanía estatal y por tanto es monopolizada por el Estado, existen casos en los estos pueden ceder su ejercicio a tribunales internacionales. ${ }^{45}$ En la medida en que la potestad jurisdiccional es propia del Estado, solo este puede cederla.

54. La cesión del ejercicio de la potestad jurisdiccional a un tribunal internacional -i.e. la cesión de aquellos poderes y atribuciones para llevar a cabo la función jurisdiccional respecto de individuos - influye irremediablemente en el proceso constitucional de aprobación del tratado internacional que lo crea.

55. La atribución de potestad jurisdiccional (art. $117 \mathrm{CE}$ ) a un tribunal internacional supone la atribución a «una organización o institución internacional el ejercicio de competencias derivadas de la Constitución» (art. $93 \mathrm{CE}$ ). Y, por ello, el tratado internacional precisa de la aprobación de las Cortes Generales mediante ley orgánica.

56. Esto supuso v.gr. que el Estatuto de Roma que instituyó la Corte Penal Internacional se tramitase por este procedimiento - y no la creación de determinados Comités de Derechos Humanos- ${ }^{46}$ Como afirmó el Consejo de Estado en su Dictamen 1374/1999 — y como también consideraba el Ministerio de Asuntos Exteriores- el Estatuto suponía «la transferencia a la CPI de potestades jurisdiccionales que la Constitución reserva en exclusiva a los Juzgados y Tribunales integrantes del Poder Judicial (artículo 117.3 CE)». ${ }^{47}$

57. Por ello, debe entenderse que existe una transferencia del ejercicio de la potestad jurisdiccional del Estado (art. $117 \mathrm{CE}$ ) cuando se crea un tribunal internacional con jurisdicción sobre aquellos individuos sometidos a la jurisdicción del Estado español. A través de esta atribución se dota al tribunal internacional de aquellos poderes necesarios para llevar a cabo la función jurisdiccional respecto de ellos.

58. Por otra parte, en relación con el orden jurisdiccional contencioso-administrativo, el art. 24 LOPJ determina que «será competente, en todo caso, la jurisdicción española cuando la pretensión

45 «El principio del monopolio estatal de la jurisdicción también significa que la función jurisdiccional la define el propio Estado, siendo una materia en la que no deben interferir otros Estados u organizaciones supranacionales, salvo que el propio Estado lo consienta y en la medida en que lo consienta. Esto sucede normalmente como consecuencia de la integración activa en organizaciones internacionales (v.g., la Unión Europea, con su sistema judicial; o la ONU, a través del Tribunal Penal Internacional)» (F. GASCón InChausti, Derecho Procesal Civil, op. cit., p. 34).

${ }^{46}$ STC núm. 70/2002 de 3 abril [RTC 2002/70]: «[L]as «observaciones» que en forma de Dictamen emite el Comité no son resoluciones judiciales, puesto que el Comité no tiene facultades jurisdiccionales (como claramente se deduce de la lectura de los arts. 41 y 42 del Pacto)». En el mismo sentido se ha dicho que «conforme a la cual el Comité de Derechos Humanos de la ONU no tiene carácter jurisdiccional, de modo que sus resoluciones o dictámenes carecen de aptitud para crear una doctrina o precedente que pudiera vincular a esta Sala de lo Penal del Tribunal Supremo» STS (Sala de lo Penal) núm. 338/2015 de 2 junio [RJ 2016 6668]. En el mismo sentido, C. GutiérREz EsPADA, "La aplicación en España de los dictámenes de comités internacionales: la STS 1263/2018, un importante punto de inflexión”, Cuadernos de Derecho Transnacional (octubre 2018), Vol. 10, No 2, pp. 836-851.

47 Dictamen del Consejo de Estado 1374/1999 relativo al Estatuto de Roma que instituye la Corte Penal Internacional, hecho en Roma el 17 de julio de 1998. «La función que cumplen los, preceptos mencionados es, en definitiva, permitir la transferencia a la CPI de potestades jurisdiccionales que la Constitución reserva en exclusiva a los Juzgados y Tribunales integrantes del Poder Judicial (artículo 117.3 CE), por lo que entiende el Consejo de Estado que el mecanismo del artículo 93 CE ampara una cesión tal del ejercicio (por lo demás, complementario, siempre y cuando España no las ejerza realmente por alguna de las razones mencionadas) de las referidas competencias. Toda atribución del ejercicio de competencias derivadas de la Constitución a una organización o institución internacional implica el reconocimiento de una intervención (con desplazamiento total o parcial de los órganos españoles, según los casos) de poderes internacionales o supranacionales en el ejercicio de competencias derivadas de la Constitución. Tratándose de competencias judiciales, resulta inherente a la transferencia de su ejercicio el admitir la existencia de instancias por encima de los órganos jurisdiccionales españoles que resultarán habilitadas para pronunciarse sobre hechos y materias en los que éstos, hasta el presente, tienen la potestad última de decir el derecho [...] Y, en mérito de lo expuesto, el Consejo de Estado es de dictamen: Que la prestación del consentimiento del Estado para obligarse por medio del Estatuto de Roma de la Corte Penal Internacional requiere autorización de las Cortes Generales mediante ley orgánica aprobada al amparo del artículo 93 de la Constitución"». 
que se deduzca se refiera a disposiciones de carácter general o a actos de las Administraciones Públicas españolas». El Consejo de Estado tradicionalmente ha considerado que los APPRIS deben tramitarse conforme el art. 94.1.e) CE porque, entre otras cuestiones, suponen una modificación del ámbito de la jurisdicción contencioso-administrativa delimitado en la LOPJ. ${ }^{48}$ En su Dictamen 1436/1993 relativo al Convenio CIADI se decía que el «sometimiento a arbitraje [...] reduce el ámbito de la jurisdicción de los Tribunales españoles, tal y como se define éste en la Ley Orgánica del Poder Judicial». ${ }^{49}$

59. No consideramos que la posibilidad de someter una controversia a arbitraje — nacional o internacional, comercial o de inversiones - suponga una modificación de la jurisdicción estatal. De ser así, lo sería cualquier ampliación o modificación de las materias arbitrables. En la medida en que los órganos judiciales sigan manteniendo la jurisdicción para conocer de la materia, no existe una modificación de la jurisdicción estatal; existe, más bien, el reconocimiento de la facultad individual de renunciar al derecho subjetivo público a servirse de ella para someter la resolución de su controversia jurídica a un particular denominado árbitro.

60. Dicho esto, algo distinto sucede en relación con el «tribunal» permanente creado por el CETA. En la medida en que el tratado internacional carece de efecto directo, en este caso sí se están «sustra[yendo] diferencias a la competencia jurisdiccional de los Estados miembros» (Dictamen 2/15 TJUE). ${ }^{50}$ Existe una reducción del ámbito de la jurisdicción de los tribunales españoles, pues no podrán conocer de reclamaciones patrimoniales ni de pretensiones de responsabilidad frente a «disposiciones de carácter general o a actos de las Administraciones Públicas españolas» basadas en un tratado internacional que, no debe olvidarse, una vez publicado forma parte del ordenamiento jurídico interno (art. $96 \mathrm{CE})$.

${ }^{48}$ En este sentido se ha pronunciado el Consejo de Estado en los más de 50 dictámenes en relación con los distintos APPRIS celebrados por España. Ha dicho, v.g., que «el sometimiento a arbitraje de las controversias que puedan surgir entre la Administración española y los inversores checos o eslovacos viene a modificar el ámbito de la jurisdicción que, según nuestra Ley Orgánica del Poder Judicial, corresponde a los tribunales del orden contencioso-administrativo» (Dictamen 491/1991 relativo al Acuerdo de Fomento y Protección recíproca de Inversiones entre España y La República Federativa Checa y Eslovaca); «el sometimiento a arbitraje de las controversias entre la Administración española y los inversores chilenos reduce el ámbito de jurisdicción que, según la Ley Orgánica del Poder Judicial, corresponde a los tribunales del orden contenciosoadministrativo» (Dictamen 92/1992 relativo al Acuerdo entre España y Chile para la Protección y Fomento Recíprocos de Inversiones, y Protocolo anejo); «este Alto Cuerpo Consultivo entiende que el eventual sometimiento a arbitraje de las controversias entre los inversores mexicanos y la Administración española (previsto en el artículo XI del Acuerdo y en el Apéndice) reduciría el ámbito de jurisdicción reconocido en el artículo 24 de la Ley Orgánica del Poder Judicial a los Tribunales españoles del orden contencioso-administrativo» (Dictamen 2126/1995 relativo a Acuerdo para Promoción y Protección Recíproca de Inversiones entre España y los Estados Unidos Mejicanos); «el eventual sometimiento a arbitraje de las controversias entre los inversores de la República de Bolivia y la Administración española, que permite el artículo 11 del Acuerdo, podría suponer una reducción del ámbito de jurisdicción reconocido en el artículo 24 de la Ley Orgánica del Poder Judicial a los Tribunales españoles del orden contencioso-administrativo» (Dictamen 954/2001 relativo al Acuerdo entre España y Bolivia para protección recíproca de inversiones); «el sometimiento a arbitraje de las controversias entre los inversores de la otra Parte contratante y la Administración española, contemplado en su artículo 9, podría reducir el ámbito de jurisdicción reconocido en el artículo 24 de la Ley Orgánica 6/1985, de 1 de julio, del Poder Judicial, a los Tribunales españoles del orden jurisdiccional contencioso-administrativo» (Dictamen 1953/2009 relativo al Acuerdo para la promoción y protección recíproca de inversiones entre el Reino de España y el Estado de Qatar).

${ }^{49}$ Además, el Consejo de Estado añadía que «aunque en el Convenio se dispone que el sometimiento a arbitraje estará condicionado al consentimiento de las Partes, una vez prestado éste el Estado se compromete a acatar y cumplir el laudo, sin que pueda ser objeto de apelación, reduciéndose, en consecuencia, la jurisdicción de los Tribunales españoles [...] Debe concluirse, pues, que es necesaria la autorización de las Cortes Generales al ser de aplicación el artículo 94.1 de la Constitución, apartado e)». En relación con el CETA, no hay ninguna referencia a la limitación de la jurisdicción española en el Dictamen 19/2017 del Consejo de Estado.

${ }^{50}$ Por ello, el TJUE declaró contrarios al Derecho de la UE los APPRIS intracomunitarios, ya que mediante estos «los Estados miembros se comprometen a sustraer de la competencia de sus propios tribunales y, por tanto, del sistema de vías de recurso judicial que el artículo 19 TUE, apartado 1, párrafo segundo, les impone establecer en los ámbitos cubiertos por el Derecho de la Unión» (STJUE de 6 de marzo de 2018, asunto C-284/16, Achmea, ECLI:EU:C:2018:158). 
61. Así, se han creado derechos e intereses materiales — si se prefiere, expectativas económicas - cuyo fundamento es la responsabilidad internacional del Estado y que, con arreglo al mismo Tratado que los crea, no son tutelables ante la jurisdicción ordinaria. ${ }^{51}$

La aprobación del tratado internacional al amparo del 94.1.e) CE requiere de mayoría simple (art. 74.2 CE). De ser cierta la afirmación del Consejo de Estado de que la Convención CIADI y los APPRIS - o como aquí se defiende, el CETA — suponen una modificación del art. 24 LOPJ, cabe plantearse en qué medida es razonable la posibilidad de modificar a través de este mecanismo una materia sometida a reserva de ley orgánica. ${ }^{52}$

62. La limitación de la jurisdicción española no supone automáticamente una cesión de su ejercicio. Es más, la cesión del ejercicio de la potestad jurisdiccional puede estar acompañada de una limitación de la jurisdicción nacional — jurisdiccional internacional exclusiva - o no - jurisdicción internacional complementaria, como lo es, v.gr., la de la CPI-.

63. Es la cesión del ejercicio de la potestad jurisdiccional (art. $117 \mathrm{CE}$ ) a un tribunal internacional con jurisdicción sobre individuos lo que realmente supone la atribución a «una organización o institución internacional el ejercicio de competencias derivadas de la Constitución» (art. $93 \mathrm{CE}$ ). A nuestro juicio, es deseable que en aras de la precisión del lenguaje, en aquellos casos en los que puedan intervenir particulares, se reserve la denominación de tribunal internacional a aquellos órganos internacionales dotados de genuina potestad jurisdiccional.

64. De un análisis del sistema de protección de inversiones del CETA parece llegarse a la conclusión de que no existe en él una cesión del ejercicio de la potestad jurisdiccional de los Estados signatarios. Es la autonomía de la voluntad de las partes el motor y fundamento de los poderes que ostenta el órgano de resolución.

65. El consentimiento del Estado y de la UE se plasma en el Tratado y el del individuo en el escrito que sirve como llave de entrada al sistema. ${ }^{53}$ Por eso, es «el consentimiento mutuo de las partes en someter dichas diferencias a conciliación o a arbitraje ${ }^{54}$ el fundamento de la vinculación y efectos jurídico-procesales reconocidos en el ordenamiento interno al laudo dictado (art. 523 LEC).

Se ha dicho que uno de los criterios para determinar si existe una cesión del ejercicio de competencias constitucionales es que los actos del ente supranacional «sean susceptibles de producir efectos directos e inmediatos en el orden interno [...] sin necesidad de mediación estatal, [de modo que] se imponga automáticamente la voluntad de la Organización». ${ }^{55}$ Conforme el art. 8.41 CETA «un laudo definitivo con arreglo a la presente sección es un laudo arbitral que se considera relacionado con demandas que se derivan de una relación o transacción comercial a efectos del artículo 1 de la Convención de Nueva York». Y, por lo tanto, se someterá el reconocimiento y ejecución del laudo al referido Convenio (art. 46 LA). ${ }^{56}$

${ }^{51}$ En el Dictamen 19/2017 del Consejo de Estado sobre el CETA no existe ninguna referencia al respecto.

${ }^{52}$ Solo el Título V del Libro VIII de la LOPJ tiene rango de ley ordinaria (DF $1^{\text {a }}$ LOPJ).

${ }^{53}$ Según el preámbulo del Convenio CIADI, «la mera ratificación, aceptación o aprobación de este Convenio por parte del Estado Contratante, no se reputará que constituye una obligación de someter ninguna diferencia determinada a conciliación o arbitraje, a no ser que medie el consentimiento de dicho Estado». Sobre el consentimiento en el tradicional arbitraje de inversiones vid. F. J. PASCUAL VIVES, "El arbitraje de inversiones", op. cit., pp. 4-14.

${ }^{54}$ Preámbulo del Convenio CIADI.

55 A. Remiro Brotons, “Comentario a los arts. 93 y 94”, en O. Alzaga Villamil (dir.), Comentarios a la Constitución Española de 1978. Tomo VII. Artículos 81 a 96, Cortes Generales. Editoriales de Derecho Reunidas, Madrid, 1998, pp. 532-534.

${ }^{56}$ En este sentido es de interés el Auto del TSJ de Madrid (Sala de lo Civil y Penal) núm. 24/2014 de 26 de septiembre [AC 2014\2022] en el que se concede el exequátur en base al Convenio de Nueva York de 10 de junio de 1958 a un laudo arbitral en materia de inversiones frente a la República Árabe de Siria dictado por la Corte Permanente de Arbitraje con sede en La Haya. En relación con el nuevo sistema, se ha planteado que las dudas en torno a la naturaleza del tribunal CETA puede suponer que los órganos judiciales nacionales concluyan que este no tiene naturaleza arbitral y no reconozcan sus resoluciones 
Sin embargo, si la demanda se presenta conforme al Convenio CIADI el laudo se someterá al régimen del de la Sección 6 Capítulo IV del Convenio. Según este, el laudo es obligatorio para las partes y «no podrá ser objeto de apelación ni de cualquier otro recurso» (art. 53). Así, el Estado «reconocerá al laudo dictado conforme a este Convenio carácter obligatorio y hará ejecutar dentro de sus territorios las obligaciones pecuniarias impuestas por el laudo como si se tratare de una sentencia firme dictada por un tribunal existente en dicho Estado» (art. 54). Por eso se ha dicho que los laudos CIADI no requieren de ningún exequátur para producir sus efectos en el ordenamiento interno. ${ }^{57}$ Es posible plantearse en qué medida la imposibilidad de control por los órganos judiciales nacionales y los efectos de estos laudos suponen o no la producción de «efectos directos e inmediatos».

66. Una conclusión en otro sentido llevaría irremediablemente a la conclusión de que el CETA -y probablemente también el Convenio CIADI- debió tramitarse conforme al art. 93 CE por suponer una cesión del ejercicio de la potestad jurisdiccional estatal (art. $117 \mathrm{CE}$ ) al crear tribunales internacionales con jurisdicción sobre particulares y no a través del art. $94 \mathrm{CE}$ —como finalmente sucedió en ambos casos-.

\subsection{El «tribunal» permanente de inversiones del CETA: un arbitraje internacional obligatorio}

67. Parece que es la permanencia del «tribunal» y de sus miembros el principal elemento que lleva a calificarlo de sistema judicial o cuasi-judicial. Sin embargo, la existencia de tribunales arbitrales permanentes ya es una posibilidad en el arbitraje internacional de inversiones. El propio art. 1.2 del Convenio de Nueva York contempla que los laudos podrán ser dictados «por los órganos arbitrales permanentes a los que las partes se hayan sometido». ${ }^{58}$ Por eso, esta no es una característica que cambie por sí misma la naturaleza del sistema. ${ }^{59} \mathrm{La}$ diferencia entre un (auténtico) tribunal internacional y un tribunal arbitral debe encontrarse, como se ha dicho, en la identificación del fundamento de los poderes y facultades para llevar a cabo su función jurisdiccional.

68. En la medida en que no exista una cesión de potestad jurisdiccional y sea la autonomía de la voluntad de las partes su fundamento, el sistema de resolución de controversias incluido en el CETA

al amparo de la Convención de Nueva York. En este sentido, A. ReInISch, "Will the EU's Proposal Concerning an Investment Court System", op. cit., 19, pp. 784-786.

${ }^{57}$ «[L]a ejecución del laudo no está condicionada por la obtención de un exequátur previo en caso de que quiera solicitarse su ejecución forzosa en un Estado distinto al de la "sede" [...] De esta manera podemos llegar a afirmar que un laudo CIADI tiene un carácter internacional, equivalente al de una sentencia de un alto tribunal internacional como el Tribunal Europeo de Derechos Humanos (TEDH) [...] Ha sido subrayado por la doctrina que las sentencias de estos altos tribunales tienen unos "mecanismos propios de producción de efectos" de conformidad con su tratado constitutivo, lo que provoca que su ejecución se aleje de la citada lógica internacional-privatista. Lo mismo se puede decir de los laudos CIADI bajo el Convenio. [...] los laudos CIADI bajo el Convenio de Washington y que son notoriamente distintas a las de los demás laudos arbitrales: no existe ninguna "sede", por lo que los laudos tienen una naturaleza jurídica internacional semejante a las resoluciones de los altos tribunales internacionales; y no necesitan de un exequátur previo para su ejecución forzosa en un Estado contratante del Convenio CIADI» (J. A. RUEGA GARCíA, "Primera ejecución forzosa conocida de un laudo arbitral CIADI en España (Víctor Pey Casado y Fundación Presidente Allende c. República de Chile): sin exequátur", Cuadernos de Derecho Transnacional, (Marzo 2014), Vol. 6, № 1, pp. 421, 429). En el mismo sentido, A. ReINISCH, "Will the EU's Proposal Concerning an Investment Court System", op. cit., 19, p. 781.

${ }^{58}$ En relación con este precepto se ha dicho que «[t]he travaux préparatoires of the Convention indicate that even a permanent dispute settlement institution can be regarded as arbitration and that what was crucial was the "voluntary nature of arbitration, based on "will" or "agreement" of the parties, as opposed to any type of adjudication based on "compulsory", or "mandatory" jurisdiction, imposed on the parties "regardless of their will".'Thus, even where the parties may not be able to appoint 'their' arbitrators, they must still be able to freely consent to such dispute settlement [...] On this basis, it seems justified to conclude that even a semi-permanent dispute settlement institution with panel members that have been appointed by states and not by the parties to a specific dispute can qualify as arbitration» (A. ReINISCH, "Will the EU's Proposal Concerning an Investment Court System”, op. cit., 19, pp. 767-768).

${ }^{59}$ En este sentido, la Resolución de 28 de agosto de 2019 de la $18^{\circ}$ Comisión del Instituto de Derecho Internacional: «Determining that its consideration of this question should consider the position of both arbitral tribunals, which are appointed ad hoc to decide a particular case ('arbitral tribunal') and any standing tribunal that is constituted now or in the future to decide investment disputes ('permanent tribunal')» (énfasis añadido). 
tiene irremediablemente la naturaleza de un arbitraje internacional y, en consecuencia, debe sostenerse que su «tribunal» permanente es un tribunal arbitral internacional. ${ }^{60} \mathrm{El}$ conjunto de poderes del tribunal arbitral y los efectos ejecutivos del laudo tienen su fundamento en esta voluntad de las partes. ${ }^{61}$

69. A esto se añade unos datos formales, pero reveladores: las resoluciones del «tribunal» se denominen «laudos», se aplican el Convenio CIADI o el Convenio de Nueva York de 1958 y se identifica la Secretaría del «tribunal» con la Secretaría del CIADI. Por ello, como acertadamente concluye IRURETAGoiena AgiRReZABalaga, el «tribunal» del CETA «no llega a abandonar su naturaleza arbitral». ${ }^{62}$

70. Por otro lado, ya se ha señalado el «carácter obligatorio de la competencia» del tribunal arbitral permanente creado por el CETA, ya que «toda acción basada directamente en las disposiciones de ese Acuerdo deberá ejercitarse ante [éll]». ${ }^{63} \mathrm{Si}$ se llega a la conclusión de que el sistema es el propio de un arbitraje de inversiones, entonces hay que concluir que los tratados de libre comercio de nueva generación instauran un arbitraje obligatorio respecto de las reclamaciones basadas en ellos. ${ }^{64}$ Sentado todo lo anterior, se puede ya analizar desde una perspectiva nacional la compatibilidad de este arbitraje obligatorio con el derecho a la tutela judicial efectiva.

\section{Un análisis desde la perspectiva del derecho a la tutela judicial efectiva}

\subsection{La compatibilidad del arbitraje de inversiones del CETA con el art. 24 CE}

71. Como se sabe, igual que la UE está sometida a los Tratados y a la CDFUE en su actuación exterior (Dictamen 1/17 TJUE), «[1]os poderes públicos españoles no están menos sujetos a la Constitución cuando actúan en las relaciones internacionales o supranacionales que al ejercer ad intra sus

\footnotetext{
${ }^{60}$ «Aunque el Acuerdo propuesto utiliza el término «Tribunal», lo que podría dar a entender que se trata de un auténtico órgano jurisdiccional, instaura, sin embargo, un mecanismo que se inspira, en gran medida, de las normas de arbitraje [...] como la Comisión señaló acertadamente durante la vista, que dicho órgano se inspire en los sistemas judiciales no lo convierte en un órgano jurisdiccional, en el sentido propio y pleno de este término, aunque tampoco hace de él un mero órgano arbitral tradicional» (Conclusiones del Abogado General de 29 de enero de 2019 al Dictamen 1/17).

${ }^{61}$ «El mecanismo de solución de diferencias que constituye el arbitraje de inversión se asienta, desde su origen, en la voluntad de las Partes contratantes de externalizar la solución de las diferencias que enfrentan a los inversores extranjeros y el Estado receptor» (Conclusiones del Abogado General de 29 de enero de 2019 al Dictamen 1/17).

62 «[S]e crea un Tribunal, que evita la calificación de arbitral, compuesto por quince "miembros" -no habla ni de árbitros ni de jueces- $[\ldots]$ 34. La composición permanente del tribunal y la introducción de una segunda instancia de apelación sugieren un desplazamiento del sistema de solución de diferencias inversor-estado hacia un modelo más "judicial". Efectivamente, la voluntad de alejarse del modelo arbitral tradicional [...] No obstante, nada más lejos de la realidad; la naturaleza arbitral del mecanismo, hoy, sigue estando muy presente en el nuevo ISDS, y ello a pesar de los esfuerzos de las Partes en evitar cualquier calificación del mecanismo como arbitral [...] Es elocuente la exigencia de que el consentimiento satisfaga los requisitos que imponen el Convenio del CIADI, el Reglamento del mecanismo complementario y el Convenio de Nueva York de 1958. [...] Por su parte, resultan especialmente significativas, por una parte, la identificación de la Secretaría del Tribunal con la Secretaría del CIADI y, por otra, la aplicación del Convenio del CIADI y del Convenio de Nueva York en la ejecución de las decisiones dictadas por el Tribunal de Inversiones o el Tribunal de Apelación. El funcionamiento del nuevo Sistema de Tribunales de Inversión, por tanto, sigue estrechamente vinculado a normas e instrumentos del arbitraje de inversiones. [...] En cualquier caso, atendiendo a todos los elementos que se congregan en el nuevo mecanismo ISDS, resulta posible apreciar en este un sistema cuando menos híbrido, un arbitraje del CIADI "tuneado" o modificado, y hasta cierto punto desnaturalizado, que no llega a abandonar su naturaleza arbitral [...] las principales novedades que introduce el CETA y que permiten, con todas las reservas, hablar de un nuevo paradigma del sistema de arreglo de diferencias inversor-Estado, cada vez más cercano a lo "judicial" y que rehúye nombrar la palabra maldita: arbitraje. No obstante, hay aspectos desconcertantes de la propuesta que cuestionan o, al menos, hacen dudar de esta última afirmación; de forma particular, la equívoca naturaleza del mecanismo y el hecho de tratarse de un modelo inacabado y "temporal", lo que evidencia que nos encontramos ante un mecanismo que no es lo que pretende ser, ni pretende ser lo que es. ¿Acaso cabe mayor despropósito?» (I. IrURETAGOIENA AgirREZABALAGA, "El capítulo sobre inversiones", op. cit., pp. 82-86, 101).

${ }^{63}$ Dictamen 1/17 del Tribunal de Justicia (Pleno) de 30 de abril de 2019, p. 198.

${ }^{64} \mathrm{Se}$ ha planteado su calificación como arbitraje obligatorio (I. IRURETAGOIENA AgIRREZABALAGa, "El capítulo sobre inversiones", op. cit., p. 87).
} 
atribuciones». No es posible «disponer de la Constitución misma, contrariando, o permitiendo contrariar, sus determinaciones» a través de tratados internacionales.$^{65}$ Dicho esto, cabe analizar el arbitraje de inversiones creado por CETA desde una perspectiva constitucional al amparo del derecho a la tutela judicial efectiva (art. $24 \mathrm{CE}$ ).

72. Conforme a la consolidada doctrina del $\mathrm{TC}$, el arbitraje es una renuncia puntual al ejercicio del derecho a la tutela judicial efectiva en relación con una o varias controversias de una relación jurídica de naturaleza contractual o extracontractual: se renuncia a la tutela judicial para someter la resolución de la controversia a un particular, el árbitro. Esta renuncia al ejercicio del derecho fundamental encuentra su fundamento constitucional en la autonomía de la voluntad como manifestación de la dignidad de la persona y el libre desarrollo de su personalidad (art. $10 \mathrm{CE}$ ) y en la libertad como valor superior del ordenamiento jurídico (art. $1 \mathrm{CE}$ ) ${ }^{66}$ Son la libertad y la autonomía de la voluntad las que justifican constitucionalmente la renuncia «expresa y puntual» al ejercicio del derecho a la tutela judicial efectiva (STC 1/2018).

73. La conceptualización del arbitraje como una renuncia puntual al ejercicio del derecho a la tutela judicial efectiva es lo que explica la razón por la que las garantías procesales que operan en el procedimiento arbitral, como el derecho a la imparcialidad del árbitro o la prohibición de indefensión, son «derechos subjetivos» de naturaleza legal: «no son garantías derivadas — con el carácter de derechos fundamentales - del art. $24 \mathrm{CE} »{ }^{67}$ sino garantías de legalidad ordinaria derivadas de la LA que cuentan con un cauce de tutela específico: la acción de anulación del laudo. ${ }^{68}$

74. El art. $24 \mathrm{CE}$ es un derecho subjetivo de prestación cuyo único sujeto pasivo es el Estado, por cuanto solo él tiene atribuida constitucionalmente la potestad jurisdiccional que se configura como la prestación garantizada. Esto supone que no es susceptible de ser vulnerado por un particular —el árbitro-. Por ello, sería imposible interponer un recurso de amparo ante una alegada vulneración de garantías procesales constitucionales en el procedimiento arbitral. ${ }^{69}$ Como sostiene el TC, «[a]quello que, por voluntad expresa de las partes, se defiere al ámbito del proceso arbitral, por esa misma voluntad expresa de las partes queda sustraído al conocimiento del Tribunal Constitucional» (STC 176/1996).

${ }^{65}$ DTC 1/1992, de 1 de julio de 1992.

${ }^{66}$ G. Schumann Barragán, "Comentario a la STC 1/2018 de 11 de enero", op. cit., p. 404.

${ }^{67}$ STC 9/2015 de 17 de enero F.J. $5^{\text {o}}$ : «Es indudable que quienes someten sus controversias a un arbitraje de equidad tienen un derecho subjetivo a la imparcialidad del árbitro (art. 12.3 de la Ley de arbitraje de 1988 [ RCL 1988, 2430 y RCL 1989, 1783] y art. 17 de la Ley 60/2003, de 23 de diciembre [ RCL 2003, 3010] , de arbitraje) y a que no se les cause indefensión en la sustanciación de las actuaciones arbitrales (art. 21.1 de la Ley de arbitraje de 1988 y art. 24.1 de la Ley de arbitraje de 2003), derechos que derivan de la misma configuración legal del arbitraje como forma de heterocomposición de los conflictos entre ellos. Pero esos derechos tienen precisamente el carácter de derechos que se desenvuelven en el ámbito de la legalidad ordinaria y que se tutelan, en su caso, a través del recurso o acción de anulación que la regulación legal del arbitraje -por medio de motivos de impugnación tasados- concede a quienes consideren que aquéllos han sido vulnerados. Como ya se ha expuesto, sin embargo, la imparcialidad del árbitro y la prohibición de indefensión en el arbitraje no son garantías derivadas -con el carácter de derechos fundamentales-del art. $24 \mathrm{CE}$, cuyas exigencias sólo rigen, en lo que atañe ahora a las concretas alegaciones que se están examinando, para el proceso - actuaciones jurisdiccionales- en el que se pretende la anulación del Laudo y para el órgano judicial que lo resuelve» (énfasis añadido).

${ }^{68}$ J. Remón Peñalver, "Orden público y acción de anulación” en M. J. Menéndez Arias (coord.), Anuario de arbitraje 2017, Aranzadi, 2017, p. 416. En el mismo sentido, también J. Remón PeÑalver, "El arbitraje ante el Tribunal Constitucional" en F. Ruiz Risueño, J. C. Fernández Rozas, (coords.), El arbitraje y la buena administración de la justicia. Libro conmemorativo del 30 aniversario de la Corte Civil y Mercantil de Arbitraje (CIMA), Tirant lo Blanch, 2019, pp. 58-62.

${ }^{69} \mathrm{El}$ art. $24 \mathrm{CE}$ solo se proyecta sobre aquellas actuaciones judiciales relacionadas con el arbitraje. En este sentido la STC núm. 136/2010 de 2 de diciembre: «las garantías contenidas en el derecho a la tutela judicial efectiva (art. 24.1 CE) sólo pueden ser proyectadas respecto del control jurisdiccional que se desarrolle sobre las fases del procedimiento arbitral previstas en la legislación, entre las más relevantes, la formalización judicial del arbitraje, el recurso o acción de anulación y la ejecución forzosa del laudo. Y STC núm. 9/2005 de 17 de enero: «sólo pueden examinarse aquí las vulneraciones alegadas en la demanda de amparo de diversas garantías del art. $24 \mathrm{CE}$ con respecto a la Sentencia de la Audiencia Provincial impugnada, pero no con respecto al Laudo arbitral, que ha de quedar excluido del objeto de este proceso constitucional». En el mismo sentido, la STC 176/1996 de 11 de noviembre. 
75. La autonomía de la voluntad como fundamento de la institución arbitral supone que en nuestro ordenamiento sean inconstitucionales aquellas normas que imponen un arbitraje obligatorio. Y es que, si la autonomía de la voluntad es el elemento legitimador del arbitraje, «[e]llo quiere decir que la falta de la necesaria concurrencia de la voluntad de ambas partes litigantes para someterse a este mecanismo extrajudicial de resolución de conflictos y su imposición a una de ellas, en principio, no se compadece bien con el básico aspecto contractual del arbitraje y con el derecho fundamental a la tutela judicial efectiva que garantiza el derecho de acceso a los órganos jurisdiccionales (art. 24.1 CE)» (STC 1/2018). Esta es la doctrina consolidada por nuestro TC en la STC 174/1995, respecto del art. 38.2 LOTT; mantenida en la STC 352/2006, respecto de la nueva redacción dada a ese mismo precepto tras su declaración de inconstitucionalidad; y reafirmada, en fechas más recientes, en la STC 1/2018, respecto del art. 76 e) LCS. ${ }^{70}$

76. Con la doctrina del TC, resulta superfluo todo análisis sobre la adecuación de las garantías procesales arbitrales con el art. $24 \mathrm{CE}$. La validez de la institución arbitral depende en nuestro sistema constitucional en exclusiva de la concurrencia de la autonomía de la voluntad material del individuo. En la medida en que esta no concurra, el arbitraje será obligatorio y, por tanto, supondrá una limitación del derecho a la tutela judicial efectiva.

77. En relación con el sistema creado por el CETA, aunque formalmente este exija que el inversor consienta el arbitraje, la realidad es que no tiene ninguna otra opción: el tribunal arbitral permanente del CETA tiene «carácter obligatorio» (Dictamen 1/17). La autonomía de la voluntad que legitima el arbitraje presupone que el sometimiento a él sea fruto de un acto de autodeterminación real del individuo, que solo concurre cuando existen alternativas razonables. ${ }^{71} \mathrm{La}$ falta de alternativas razonables al arbitraje supone que el sometimiento no sea un acto de autodeterminación libre.

Además del carácter obligatorio del arbitraje, a través del «tribunal» permanente también se imponen los árbitros que conocerán de la controversia. Se ha dicho que en abstracto es posible la existencia de tribunales arbitrales permanentes. Sin embargo, en todo caso el sometimiento a ellos depende de las partes. En este caso se impone el sistema y a los propios árbitros — elegidos en el Comité Mixto del CETA—. ${ }^{72}$

\footnotetext{
${ }^{70}$ En este caso la STC núm. 1/2018 de 11 de enero: «el artículo 76 e) LCS vulnera el derecho a la tutela judicial efectiva garantizado en el artículo $24 \mathrm{CE}$, pues impide el acceso a la jurisdicción de los juzgados y tribunales de justicia que, ante la falta de la voluntad concurrente de los litigantes, son los únicos que tienen encomendada constitucionalmente la función de juzgar y hacer ejecutar lo juzgado [...]. El precepto ha eliminado para una de las partes del contrato la posibilidad de acceder a los órganos jurisdiccionales, en cuanto fija una vía alternativa excluyente de la jurisdiccional, cuya puesta en marcha depende únicamente de la voluntad de una de las partes [...] Por ello, resulta contrario a la Constitución que la Ley de contrato de seguro suprima o prescinda de la voluntad de una de las partes para someter la controversia al arbitraje, denegándole la posibilidad en algún momento de solicitar la tutela jurisdiccional». STC núm. 174/1995 de 25 de noviembre: «La autonomía de la voluntad de las partes -de todas las partes- constituye la esencia y el fundamento de la institución arbitral, por cuanto que el arbitraje conlleva la exclusión de la vía judicial. Por tanto, resulta contrario a la Constitución que la Ley suprima o prescinda de la voluntad de una de las partes para someter la controversia al arbitraje de la Junta que es lo que hace en el párrafo primero del artículo 38.2. La primera nota del derecho a la tutela consiste en la libre facultad que tiene el demandante para incoar el proceso y someter al demandado a los efectos del mismo. Quebranta, por tanto, la esencia misma de la tutela judicial tener que contar con el consentimiento de la parte contraria para ejercer ante un órgano judicial una pretensión frente a ella. Esto es exactamente lo que hace el artículo 38.2, párrafo primero, de la LOTT, que, al exigir un pacto expreso para evitar el arbitraje y acceder a la vía judicial, está supeditando el ejercicio del derecho a la tutela judicial efectiva de una de las partes al consentimiento de la otra, lo que, por las razones que han quedado expuestas, resulta contrario al artículo 24.1 de la Constitución». Y la STC núm. $352 / 2006$ de 14 de diciembre en los mismos términos aunque con distinto resultado respecto del enjuiciamiento constitucional de la nueva redacción dada al art. 38 de la LOTT: «a) El precepto en su nuevo texto [...] hemos de concluir que la consecuencia jurídica cuestionada — sometimiento al arbitraje—- en cuanto puede ser excluida por la declaración de una sola de las partes, cuya formulación, además, puede producirse incluso después de la celebración del contrato, no resulta desproporcionada. [...]. No se aprecia, pues, la vulneración del art. 24.1 CE en relación con el art. 117.3 CE que se atribuye al precepto cuestionado».

${ }^{71}$ Para un análisis de la relación entre alternativas razonables y un acto de autodeterminación del individuo vid. J. ALFARo ÁGUILA-REAL, "La autonomía privada y derechos fundamentales" en Anuario de Derecho Civil, Fascículo 1, 1993, pp. 57-122; del mismo autor, Las condiciones generales de la contratación, Civitas, Madrid, 1991, pp. 54-56; y "Función económica y naturaleza jurídica de las condiciones generales de la contratación" en A. Menéndez Menéndez, L. Diez-Picazo y Ponce De León, (dirs.), J. Alfaro Águila-Real. (coord.), Comentarios a la Ley sobre condiciones generales de la contratación, Civitas, Madrid, 2002, pp. 82-91.

72 Árbitros, no se olvide, vinculados con la interpretación hecha del tratado por el Comité Mixto.
} 
78. Por eso, debe considerarse que el CETA impone un arbitraje obligatorio que, conforme a la doctrina de nuestro TC, supone una limitación del derecho a la tutela judicial efectiva de los justiciables —españoles y extranjeros - (art. $24 \mathrm{CE})$.

Como se sabe, la soberanía de los Estados es el fundamento de las inmunidades de jurisdicción y ejecución que a estos se les reconocen (art. 22 LOPJ). Sin embargo, y como también debe recordarse, estas inmunidades no son absolutas: son susceptibles de ser renunciadas expresas o tácitamente. ${ }^{73}$ En abstracto, con los tradicionales APPRIS - de tener efecto directo- existe la posibilidad de que cualquier inversor español pretenda ante un órgano judicial español frente al Estado extranjero receptor de la inversión la condena al pago de una cantidad pecuniaria derivada de su responsabilidad internacional con fundamento en el tratado. Con la falta de efecto directo del CETA esta posibilidad también queda limitada.

79. Esta vulneración no debe supone per se la inconstitucionalidad del CETA. El Tratado podría ser constitucional si se considera que existe una limitación admisible del derecho fundamental. ${ }^{74}$

80. Como se sabe, además de sus límites intrínsecos, los derechos fundamentales podrán ser limitados cuando entran en colisión con otros derechos fundamentales o con otros bienes constitucionalmente protegidos. ${ }^{75}$ La constitucionalidad del CETA en este punto depende así de la identificación de algún límite extrínseco que legitime esa limitación del derecho a la tutela judicial efectiva que supone el arbitraje obligatorio.

81. Durante la autorización previa de las Cortes Generales para la prestación del consentimiento al CETA por parte del Reino de España (art. $94 \mathrm{CE}$ ) se propuso en el Congreso y en el Senado el requerimiento al TC para que se pronunciase sobre su constitucionalidad (art. 95.2 CE), pero la proposición fue rechazada.$^{76}$ En este contexto, solo a través de la interposición de alguna futura cuestión o autocuestión de inconstitucionalidad será posible que el TC se pronuncie sobre la compatibilidad del CETA con la CE. ${ }^{77}$

\subsection{La compatibilidad del arbitraje de inversiones del CETA con el art. 6 CEDH}

82. En la medida en que España - a diferencia de la UE, por ahora - es parte del CEDH, también es oportuno hacer un análisis del arbitraje obligatorio incorporado en él desde la perspectiva del art. $6 \mathrm{CEDH}$. A diferencia de la doctrina constitucional de nuestro TC, el TEDH ha considerado que un arbitraje obligatorio no vulnera el art. $6 \mathrm{CEDH}$ siempre que este cumpla con las garantías procesales del derecho a un juicio justo.

\footnotetext{
${ }^{73}$ En general, sobre esto, vid. F. GASCón Inchausti Inmunidades Procesales y Tutela Judicial frente a Estados Extranjeros, Aranzadi, Cizur Menor, 2008.

${ }^{74}$ G. Schumann BarRagán, "Comentario a la STC 1/2018 de 11 enero", op. cit., pp. 412-417.

${ }^{75}$ STC 11/1981, de 8 de abril, F.J. $7^{\circ}$.

${ }^{76}$ «Propuesta de planteamiento del requerimiento previsto en el artículo 95.2 de la Constitución en relación con el acuerdo económico y comercial global entre Canadá, por una parte, y la Unión Europea y sus Estados Miembros, por otra, hecho en Bruselas el 30 de octubre de 2016 (número de expediente 231/000001)», Diario de Sesiones del Congreso de los Diputados. Pleno y Diputación Permanente. Núm. 55, 18 de mayo de 2017. «Solicitud de requerimiento al Tribunal Constitucional para que se pronuncie sobre la constitucionalidad del Acuerdo Económico y Comercial Global entre Canadá, por una parte, y la Unión Europea y sus Estados miembros, por otra, hecho en Bruselas el 30 de octubre de 2016. (751/000001)», (Boletín Oficial de las Cortes Generales. Senado XII Legislatura. Núm. 153, 2 de octubre de 2017, p. 76).

77 «Por otra, aún finalizado este plazo, de conformidad con lo previsto en el art. 29 LOTC, puede promoverse por los jueces y tribunales, ya sea de oficio o a instancia de parte, una cuestión de inconstitucionalidad cuando consideren, en algún proceso, que la disposición de un tratado internacional, aplicable al caso, de cuya validez dependa el fallo, pueda ser contraria a la Constitución. [...] Es fácil percibir, por consiguiente, la amplitud con que nuestro sistema constitucional contempla la posibilidad del control a posteriori de la constitucionalidad de los tratados» (P. Andrés Sáenz de SANTA María., Sistema, op. cit. [capítulo III apartado IV 7-B]).
} 
83. Según la reciente doctrina del TEDH existen dos tipos de arbitrajes: voluntarios y obligatorios. ${ }^{78}$ En los primeros, las partes con base en la autonomía de su voluntad renuncian puntualmente de forma libre e inequívoca - free and unequivocal manner - a que sus pretensiones sean tuteladas jurisdiccionalmente (art. $6 \mathrm{CEDH}) .{ }^{79}$ En los segundos, la sumisión a arbitraje es impuesta por la ley o contractualmente a la parte débil.

84. La libertad, tal como es entendida por el Tribunal, supone el poder real de renunciar o no al ejercicio del derecho fundamental, esto es, la posibilidad real de decidir si someter determinadas controversias a arbitraje. La libertad se concibe también aquí como el poder de elegir entre dos alternativas posibles.

85. La diferencia principal entre un arbitraje voluntario y uno obligatorio es, según el Tribunal, la proyección que el art. $6 \mathrm{CEDH}$ tiene sobre el procedimiento arbitral. En el caso de que se considere que estamos ante un arbitraje obligatorio, el TEDH sostiene que las garantías del art. 6 CEDH se proyectan sobre las actuaciones arbitrales. ${ }^{80}$ En un arbitraje voluntario, por el contrario, en cuanto la parte renunció válidamente a su ejercicio, no existe ninguna proyección del art. $6 \mathrm{CEDH}{ }^{81}$

86. En todo caso, la proyección de las garantías del art. $6 \mathrm{CEDH}$ no supone que este sea materialmente aplicable en el procedimiento arbitral y que pueda ser directamente vulnerado por el árbitro. Simplemente supone que sea exigible que el sistema arbitral — nacional o internacional - materialmente incorpore las mismas garantías procesales reconocidas por el art. $6 \mathrm{CEDH}$.

Como hemos dicho en otro lugar, aunque la proyección del art. $6 \mathrm{CEDH}$ en el procedimiento arbitral parezca a priori una posición más garantista, en realidad no lo es: «La proyección del art. 6 CEDH o del art. $24 \mathrm{CE}$ sobre el procedimiento arbitral es el "precio que hay que pagar" para considerar válidos los arbitrajes obligatorios -impuestos, no lo olvidemos, por ley o contrato-. A nuestro juicio es más garantista $\mathrm{y}$ acorde con la dignidad del individuo sostener que el arbitraje no puede ser impuesto en ningún caso». ${ }^{82}$

87. En este sentido, se constata que existe un distinto nivel de protección entre la CE y CEDH, algo, desde luego, que no es inusual respecto de otros derechos fundamentales. Un arbitraje obligatorio que cumpla con las garantías del art. 6 del CEDH es válido desde la perspectiva del CEDH. Un arbitraje obligatorio, sin embargo, supone una limitación del art. $24 \mathrm{CE}$ — con independencia de que en el procedimiento arbitral se asegure el cumplimiento de sus garantías-.

88. Por ello, parece deducirse que existe un mismo nivel de protección entre el art. 6 CEDH y el art. 47 CDFUE - y, por tanto, que el Dictamen 1/17 es en esto conforme con la doctrina del TEDH-. En la medida en que estamos ante un arbitraje impuesto, se proyectarían las garantías del art. 47 CDFUE. No sería una proyección material, por cuanto en todo caso el «tribunal» permanente del CETA está fuera

${ }^{78}$ G. Schumann Barragán, "Sobre la renunciabilidad del derecho a la tutela judicial efectiva a propósito del asunto Mutu y Pechstein c. Suiza” en Derecho procesal: Retos y transformación. V Memorial Manuel Serra Domínguez (en prensa).

${ }^{79} «[. .$.$] in the case of voluntary arbitration to which consent has been freely given, no real issue arises under Article 6$. The parties to a dispute are free to take certain disagreements arising under a contract to a body other than an ordinary court of law. By signing an arbitration clause the parties voluntarily waive certain rights secured by the Convention» (STEDH de 2 de octubre de 2018, as. 40575/10 y 67474/10, Mutu y Pechstein c. Suiza) (énfasis añadido).

${ }^{80}$ «In addition, a distinction must be drawn between voluntary arbitration and compulsory arbitration. If arbitration is compulsory, in the sense of being required by law, the parties have no option but to refer their dispute to an arbitral tribunal, which must afford the safeguards secured by Article 6 \& 1 of the Convention» (STEDH de 2 de octubre de 2018, as. 40575/10 y 67474/10, Mutu y Pechstein c. Suiza) (énfasis añadido).

81 «[...] in the case of voluntary arbitration to which consent has been freely given, no real issue arises under Article 6» (STEDH de 2 de octubre de 2018, Mutu y Pechstein c. Suiza). En términos similares se había pronunciado el Tribunal en la STEDH 28 de octubre de 2010 (as. 1643/2006, Suda c. Republica Checa). Vid. Tambien V. Ferreres Comella, "When arbitration is not voluntary: the case of Mutu and Pechstein v. Switzerland", Investment Arbitration Outlook, Uría Menendez, 2018, Issue 4, p. 4.

${ }^{82}$ G. Schumann Barragán, "Sobre la renunciabilidad del derecho a la tutela judicial”, op. cit. (en prensa). 
del sistema jurisdiccional de la UE (art. 19 TUE); pero supondría la exigencia de incorporar las garantías procesales del art. 47 CDFUE en el Tratado para asegurar indirectamente su efectividad.

89. Lo anterior nos llevaría a concluir que, de considerarse que se incorporan las garantías procesales del art. 47 CDFUE y del art. 6 CEDH, el arbitraje de inversiones del CETA es compatible con el CEDH y con la CDFUE. Sin embargo, en relación con el nivel de protección que asegura el art. $24 \mathrm{CE}$, este supondría una limitación del derecho a la tutela judicial efectiva. La constitucionalidad del CETA depende, en última instancia, de la validez constitucional de esta limitación.

\section{Excurso: a la espera del Tribunal Constitucional Alemán}

90. Aunque el CETA ya ha sido aprobado por la UE, no entrará en vigor hasta que sea aprobado por los distintos EE. MM. a través de sus respectivos procesos constitucionales. Por lo anterior, se ha acordado la aplicación provisional de aquellas partes del Tratado que están dentro de la competencia exclusiva de la UE. En la medida en que la protección de inversiones extranjeras distintas de las directas y el sistema de resolución de controversias son competencias nacionales y compartidas, el arbitraje de inversiones del CETA aún no es de aplicación. ${ }^{83}$

91. El CETA — que aún no ha sido aprobado en Alemania — será objeto de enjuiciamiento por parte de su Tribunal Constitucional Federal - Bundesverfassungsgericht (BVerfG) - en el seno de un procedimiento acumulado de 4 recursos de amparo - Verfassungsbeschwerden - y un recurso constitucional por conflicto de competencias. Aunque lleva algunos años posponiéndose la resolución — probablemente esperando la llegada del Dictamen 1/17-, en principio la sentencia será dictada durante el año $2020{ }^{84} \mathrm{El}$ razonamiento jurídico en que se fundan los recursos es que el CETA supone una afectación de la identidad constitucional (art. $79 G G$ ) y del principio democrático (arts. 20 y $38 G G$ ).

92. En concreto, en relación con el «tribunal» permanente del CETA, los recurrentes consideran que en la medida en que sus resoluciones serán directamente vinculantes existe una cesión de soberanía que supone una ruptura del principio de unidad jurisdiccional. ${ }^{85}$ Por tanto, parece que se parte de la tesis de que el «tribunal» permanente del CETA es un tribunal internacional al que se le ha atribuido potestad jurisdiccional.

Es de interés señalar que recientemente el $B V \operatorname{Verf} G$ también en el seno de un recuro de amparo ha declarado que el Acuerdo sobre un Tribunal Unificado de Patentes es nulo por no haber sido válidamente aprobado por el Bundestag. ${ }^{86}$ Se considera que a través del acuerdo se confieren funciones judiciales a un tribunal internacional, lo que supone una afectación de la jurisdicción alemana (art. 92 GG) y una modificación material de la Constitución que requiere la aprobación de dos tercios del Bundestag y del

${ }^{83}$ I. Iruretagoiena Agirrezabalaga, "El capítulo sobre inversiones", op. cit., pp. 51-54.

$84 \mathrm{~h}$ ttps://www.bundesverfassungsgericht.de/EN/Verfahren/Jahresvorausschau/vs_2020/vorausschau_2020.html

${ }^{85}$ BVerfG, Urteil des Zweiten Senats vom 13. Oktober 2016 - 2 BvR 1368/16: «1. a) Die Antragsteller zu I. - IV. machen im Wesentlichen geltend, ein Beschluss des Rates der Europäischen Union über die Unterzeichnung von CETA, dessen vorläufige Anwendung und den Abschluss des Abkommens verletze ihre Rechte aus Art. 38 Abs. 1 in Verbindung mit Art. 79 Abs. 3 und Art. 20 Abs. 1 und 2 GG. Die Voraussetzungen der Ultra-vires-Kontrolle sowie der Identitätskontrolle lägen vor. Die Europäische Union überschreite die ihr primärrechtlich eingeräumten Kompetenzen sowohl hinsichtlich zahlreicher von CETA erfasster Sachbereiche als auch durch Einsetzung des Investitionsgerichts. Diesem würden ohne ausreichende Rechtsgrundlage Hoheitsrechte übertragen, indem es in die Lage versetzt werde, letztverbindliche, vollstreckbare Urteile zu erlassen. CETA berühre zudem die Autonomie des Bundestages [...] Ferner sei das Rechtsstaatsprinzip beeinträchtigt, weil durch die Übertragung von Kompetenzen auf das Investitionsgericht das Rechtsprechungsmonopol durchbrochen werde. Der Antragsteller zu I. macht darüber hinaus eine Verletzung von Art. 14 Abs. 1 GG geltend».

${ }^{86}$ BVerfG, Beschluss des Zweiten Senats vom 13. Februar 2020 - 2 BvR 739/17 -. Está disponible en alemán en: https:// www.bundesverfassungsgericht.de/SharedDocs/Entscheidungen/DE/2020/02/rs20200213_2bvr073917.html;jsessionid=CAD B4AC6EF68CA7E456510D45D530F35.1_cid392 
Bundesrat (art. 79.2 GG). ${ }^{87}$ Esto no es más que una muestra de la importancia práctica de determinar la naturaleza de los órganos de resolución creados por tratados internacionales y de la necesidad de, más allá de los términos e imagen que de ellos se quiera dar, identificar si existe una auténtica cesión del ejercicio de la potestad jurisdiccional del Estado.

93. Como consecuencia de la aplicación provisional del CETA se ha solicitado al BVerfG hasta en dos ocasiones la adopción de medidas cautelares: en ambos casos estas fueron rechazadas. Las medidas tenían como finalidad que se ordenase al Gobierno Federal Alemán que impidiera cualquier actuación en el Consejo de la UE dirigida a permitir la aplicación provisional del CETA. ${ }^{88}$

Aunque la solicitud de medidas cautelares fue desestimada, el $B V \operatorname{Verf} G$ impuso al Gobierno Federal que la aplicación provisional del CETA se refiriera únicamente a los capítulos en los que la UE tiene competencia exclusiva, que hasta que se dictara la sentencia del procedimiento principal se asegurara la legitimidad democrática del Comité Mixto del CETA y que se asegurara que la República Federal Alemana pueda terminar unilateralmente la aplicación provisional del tratado en cualquier momento.

94. La sentencia del $B \operatorname{Verf} G$ podría suponer un importante hito para el análisis de la compatibilidad de este nuevo modelo de arbitraje de inversiones con la Constitución alemana, en general, y con el derecho a un proceso justo, en particular $(103 G G) .{ }^{89}$

\section{Conclusión}

95. El arbitraje de inversiones extranjeras en los tratados de libre comercio de nueva generación se enmarca en un sistema de competencias compartidas entre la UE y sus EE. MM. Esto supone que el sistema deba ser compatible con el ordenamiento comunitario y nacional, lo que impone su análisis desde la perspectiva de los arts. $47 \mathrm{CDFUE}, 24 \mathrm{CE}$ y $6 \mathrm{CEDH}$.

96. La consolidación del individuo como actor en los sistemas internacionales de resolución de controversias impone actualizar conceptos nucleares como jurisdicción y potestad jurisdiccional internacional que expliquen el conjunto de poderes y facultades de los tribunales internacionales para llevar a cabo funciones jurisdiccionales en relación con particulares sometidos, en lo que ahora interesa, a la jurisdicción del Estado español.

97. La falta de efecto directo del CETA supone de facto que el sistema de solución de controversias establecido en él es un arbitraje de inversiones obligatorio. En principio, de considerarse que cum-

\footnotetext{
87 «Unabhängig von der konkreten Ausgestaltung der Patentgerichtsbarkeit bewirkt eine Übertragung von Rechtsprechungsaufgaben unter Verdrängung deutscher Gerichte eine inhaltliche Änderung des Grundgesetzes im Sinne von Art. 23 Abs. 1 Satz 3 GG. Die rechtsprechende Gewalt wird nach Art. 92 GG durch das Bundesverfassungsgericht, die Bundesgerichte und die Gerichte der Länder ausgeübt. Jede Übertragung von Rechtsprechungsaufgaben auf zwischenstaatliche Gerichte modifiziert diese umfassende Rechtsprechungszuweisung und bedeutet insoweit eine materielle Verfassungsänderung. Sie berührt nicht nur die grundrechtlichen Garantien des Grundgesetzes, weil deutsche Gerichte insoweit keinen Grundrechtsschutz mehr gewähren können (vgl. BVerfG, Beschluss des Ersten Senats vom 6. November 2019 - 1 BvR 276/17 -, Rn. 42 ff., 54), sondern berührt auch die konkrete Ausgestaltung der Gewaltenteilung nach Art. 20 Abs. 2 Satz 2 GG» BVerfG, Beschluss des Zweiten Senats vom 13. Februar 2020 - 2 BvR 739/17 -, Rn. 157.

${ }^{88}$ La primera resolución que desestima las medidas cautelares es el BVerfG, Urteil des Zweiten Senats vom 13. Oktober 2016 - 2 BvR 1368/16. Está disponible en alemán e inglés en: https://www.bundesverfassungsgericht.de/SharedDocs/Entscheidungen/EN/2016/10/rs20161013_2bvr136816en.html;jsessionid=DBEBDDDBF278213B7C6A2C8ACBDB3E1C.2_cid393 La segunda resolución que vuelve a desestimar las medidas cautelares es el BVerfG, Beschluss des Zweiten Senats vom 07. Dezember 2016 - 2 BvR 1444/16. Está disponible en alemán e inglés en: https://www.bundesverfassungsgericht.de/SharedDocs/ Entscheidungen/EN/2016/12/rs20161207_2bvr144416en.html

${ }^{89}$ También se ha interpuesto un recurso de amparo contra el acuerdo de libre comercio UE-Singapur. En el seno de este procedimiento se solicitaron medidas cautelares que también fueron rechazadas por resolución del $B V e r f G$ de 7 de noviembre de 2019 (BVerfG, Beschluss der 2. Kammer des Zweiten Senats vom 07. November 2019 - 2 BvR 882/19 -. Está disponible en alemán en: https://www.bundesverfassungsgericht.de/SharedDocs/Entscheidungen/DE/2019/11/rk20191107_2bvr088219.html).
} 
ple con sus garantías, este puede considerarse compatible con el art. 47 CDFUE y con el art. 6 CEDH. Sin embargo, en relación con el nivel de protección que asegura el art. $24 \mathrm{CE}$, el arbitraje de inversiones del CETA supone una limitación del derecho a la tutela judicial efectiva.

98. La reciprocidad y la deseada independencia de los órganos judiciales del Estado receptor de la inversión justifican la existencia de un sistema de arbitraje internacional que permita la resolución de las controversias fuera de los sistemas judiciales nacionales. Además, es legítima y políticamente bienvenida la pretensión de dotar de transparencia al sistema y de asegurar la independencia e imparcialidad de los árbitros a través de la creación de instituciones arbitrales permanentes. Sin embargo, estos no son argumentos que conviertan en deseable la limitación del derecho a la tutela judicial efectiva de los justiciables - europeos o canadienses, multinacionales o pymes - que impone el nuevo sistema de arbitraje de inversiones obligatorio del CETA e incorporan algunos tratados internacionales en proceso de negociación que están por venir, si llegan. 